E. Pfl üger: Ueber die Titration des Harnstoffs mit Mercurinitrat. 533

(Physiologisches Laboratorium in Bonn.)

\title{
Ueber die Titration des Harnstoffs mit Mercurinitrat nach der Methode von Rautenberg und Th. Pfeiffer.
}

Von

E. Pflïger.

Theil I.

\section{Kritische Erörterung.}

Die quantitative Analyse des Stickstoffs im Harne nach Kjeldahl liefert Resultate von unvergleichlicher Schärfe, und die Zahl der Analysen, welche sich in ein paar Tagen ausführen lassen, ibertrifft bei Weitem die durch irgend welche andere Methoden erzielbare, weil viele Analysen von einem Arbeiter gleichzeitig in Angriff genommen werden können. Es scheint deshalb, als sei eine Bearbeitung älterer Methoden, deren Endzweck ebenfalls die Bestimmung des Stickstoffs im Harne ist, eine iiberflüssige Arbeit.

Der genannte Vorzug der Kjeldahl'schen Methode setzt aber ein grösseres mit Abzïgen versehenes chemisches Laboratorium voraus, und jede einzelne Analyse dauert, wenn sie sehr genaue Resultate geben soll, sehr viel länger als die Liebig'sche Titration, die in jeder Privatwohnung, ohne dass ätzende Dämpfe belästigen, in sehr kurzer Zeit ausführbar ist. Hierzu kommt als ganz besonderer Vorzug, dass nach den Untersuchungen, die ich mit Dr. Bohland ausgeführt habe, die Lieb ig 'sche Methode, wenn man die von mir beschriebene Modification befolgt, gar keine Bestimmung des Harnstoffs ist, wie man bisher annahm, sondern den Sticks to ffgehalt ziemlich annähernd im Allgemeinen zu ermitteln gestattet. Wenn es sich also um Untersuchungen handelt, in denen die einzelne Analyse in kurzer Zeit ausgefuhrt werden muss, wenn ein wohl ausgerüstetes chemisches Laboratorium nicht zu Gebote steht, und wenn annähernde Werthe genuigen, wird man auch ferner die Titration mit Mercurinitrat nicht entbehren wollen. 
Fernere Vereinfachungen dieser Methode dürften also immer willkommen sein.

In einer von Henneberg, Stohmann und Rautenberg schon im Jahre 1862 herausgegebenen Arbeit ${ }^{1}$ ) wurde ein neues, allerdings sehr einfaches Verfahren angegeben, um die Ausfüllung: des Chlors auș dem Harne zu umgehen, welche nach Liebig nöthig war.

Henneberg, Stohmann und Rautenberg hatten sich in jener 1862 herausgegebenen Untersuchung ferner der Vereinfachung bei der Liebig'schen Harnstofftitration bedient, dass sie gleich vor dem Zusatz von Quecksilberlösung etwas gebrannte Magnesia zusetzten, „so bemessen, dass die Flïssigkeit nach dem Austritiren noch deutlich saner reagirt".

Weil unbestimmte Mengen Magnesia zugesetzt und unbestimmte Menge von Säure nach dem Austitriren uibrig bleibt, ergibt sich, dass bei dieser Methode die Titration im Anfange in alkalischer, am Ende in saurer Lösung ausgeführt wird. Da ich nun gezeigt habe, dass das Endresultat erheblich differirt, je nachdem man in saurer, neutraler oder alkalischer Lösung den Harnstoff mit Mercurinitrat titrirt, so muss ein Verfahren, bei dem ein unbestimmter und von einem zum anderen Versuche veränderlicher Abschnitt der Titration in alkalischer resp. neutraler, ein anderer in saurer Reaction durchgefübrt wird, zu unrichtigen Zahlen nothwendig führen.

Auf Veranlassung Henneberg's hat dessen früherer Assistent Rautenberg die hier besprochene Modification der Liebig'schen Methode weiter auszubilden gesucht, starb aber im October 1863 am Nervenfieber vor Publication, so dass diese von Henneberg selbst in das Werk gesetzt wurde ${ }^{2}$ ).

Das Wesentlichste dieser Methode will ich mit den Worten des Autors wiedergeben ${ }^{3}$ ):

„Zuerst wurde durch eine umfassende Reihe von Titrationen, die sich auf die verschiedenartigsten Gemische von Harnstoff-Kochsalz- und Glaubersalzlösung bezogen, ermittelt, dass nur innerhalb sehr enger Mischungsverbältnisse daran zu denken gewesen wäre, auf dem beabsichtigten Wege zum Ziele zu kommen. Ins-

1) Liebig's Annalen 124, p. 192.

2) Rautenberg, Liebig's Annalen 133, p. 55.

3) Rautenberg, Annalen 133, p. 5̄ó. 
besondere ergab sich der störende Umstand, dass bei hohem Kochsalzgehalt der Mischung (z. B. $5 \mathrm{ccm} \mathrm{2 \%}$ Harnstoff und $10 \mathrm{cem}$ $2 \%$ Kochsalzlösung) die Endreaction mit Sodalösung: Entstehung eines gelben Niederschlages beim Zusammenbringen mit dem quecksilberhaltigen Probetropfen, - nieht mehr scharf, sondern von einem Probetropfen zum anderen verschwimmend hervortrat.

„Die Benutzung des bekannten Verhaltens, dass Sublimat im Gegensatz zu salpersaurem Quecksilberoxyd, durch NatronBicarbonat nicht gefällt wird, liess den Zweck dann in weit einfacherer Weise erreichen. Man wendet rämlich statt des hisher gebräuchlichen einfach kohlensauren, das doppelt kohlensaure Natron als Erkennungs mittel des Quecksilberüberschusses an und operirt im Uebrigen ganz nach der Modification des Liebig'schen Verfahrens, welches von uns a. a. 0 . beschrieben ist und wesentlich auf Folgendes hinausläuft.

"Von der harnstoffhaltigen Flüssigkeit werden zwei Proben à $15 \mathrm{ccm}$ abgemessen. Die eine davon säuert man mit einem Tropfen Salpetersäure seliwach an und fügt dann so lange von der Normalquecksilberlösung $(30 \mathrm{ccm}=15 \mathrm{~cm} 2 \%$ Harnstofflösung) hinzu, bis sich eine bleibende Triibung einstellt. Die Anzahl der hierbei verbrauchten Cubikcentimeter Quecksilberlösung bildet die Correction für Kochsalz. - Die zweite Probe dient zum Ausfällen des Harnstoffs. Man lässt die Quecksilberlösung obne vorhergehende Ansäuerung der Probe allmählich zufliessen und bewirkt die Nentralisation der beim Entstehen des Harnstoffquecksilberoxyds frei werdenden Salpetersäure durch successiven Zusatz kleiner Mengen von reinem präcipitirten kohlensauren Kalk. Zur Prüfung, ob aller Harnstoff ausgefällt ist, bringt man mit dem Glasstab einen starken Probetropfen auf eine sorgfältig gereinigte, an der Unterseite dicht mit Asphaltfirniss überzogene Glasplatte und bedeckt denselben mit einem Tropfen in Wasser aufgerührten doppelt kohlensauren Natrons, wobei das Erscheinen der ersten deutlichen Spuren einer gelben Färbung die Beendigung der Reaction anzeigt." -

Wenn man davon absieht, dass die hier befolgte Correctur resp. Umgehung der Ausfällang des Chlors, aus secundären Gründen unzulässig ist, kann das Verfahren nur dann als zwar nicht a posteriori aber a priori chemisch halbwegs correct betrachtet werden, wenn die Prïfung mit doppelt kohlensaurem Natron 
nur bei saurer Reaction der harnhaltigen Flüssigkeit geschieht und erst nach jedesmaliger Anstellung dieser Probe mit koblensaurem Kalk, der nie im Ueberschuss zugesetzt werden darf, nentralisirt wird, worauf man mit dem weiteren Zusatz der Quecksilberlösung fortfährt. Das ist aber nicht gesagt und schwer ausführbar und wir werden bald sehen, dass dieser Punkt einer neueren Arbeit über dieselbe Methode, welche wieder auf Veranlassung von Professor Henneberg durch Dr. Th. Pfeiffer ausgeführt wurde, verhängnissvoll geworden ist.

Dr. Th. Pfeiffer ${ }^{1}$ ) glaubt zu dem Ergebniss gelangt zu sein, dass die Rautenberg'sche Harnstofftitration, besonders wenn sie mit den von $\mathrm{Pfeiffer}$ ermittelten Modificationen ausgeführt wird, mein Verfahren an Sicherheit und Einfachheit bei Weitem übertrifft.

Ehe ich deshalb die Methode Pfeiffer's bespreche, muss ich die Angriffe desselben gegen mich erst erledigen.

Es sollen nicht viele Worte verloren werden, wo er mir Ansichten zuschreibt, welche ich nirgends aufgestellt habe.

Pfeiffer behauptet: „Pflüger ist hiernach der Ansicht, dass lediglich sein als ,stetige Methode" bezeichnetes Verfabren zu richtigen Resultaten führe und dass somit alle bis dahin gemachien Harnstofftitrationen ( - demnach auch zahlreiche grundlegende Stoffwechseluntersuchungen -) mit einem bedeutenden Fehler behaftet seien, den er zu $14 \%$ und mehr veranschlagt" 2).

Es war niemals meine Ansicht, dass nur meine Methode zu richtigen Resultaten führe; ich habe stets angenommen und auch ausgesprochen ${ }^{3}$ ), dass man wahrscheinlich auch nach anderem Modus als dem meinigen den Harnstoff titriren könne. Aber daศu wäre eine Untersuchung nöthig, die diesen neuen Modus mit seinen Specialbedingungen ausgearbeitet hätte, was bis dahin nicht geschehen war.

Bis zu meinen Arbeiten ${ }^{4}$ ) uber die Analyse des Harnstoffs nach Liebig's Methode war von allen den paradoxen Bedin-

1) Dr. Th. Pf e if fer, Ueber die titrimetrisehe Bestimmung des Harnstoffs in Zeitschrift für Biologie. Bd. XX, p. 540 u. folg.

2) S. Th. Pfeiffer a. a. 0., p. 540.

3) E, Pf 1 üger, Ueber die quantitative Bestinmung des Harnstoffs. Bd. 51, p. 266.

4) E. Pflüg er. Dies Archiv, 21, 248. - 23, 127. - 25, 292. 26, 289 . 
gungen, die so stark den Titer der Mercurinitratlösung beeinflussen, wesentlich Nichts bekannt. Damit habe ich den Beweis geliefert, dass die vor mir publicirten Analysen, bei denen der Harnstoff nach Liebig's Methode bestimmt worden war, wenigstens sehr oft mit schweren Fehlern behaftet sein mussten, die sicher bis $14 \%$ und noch mehr betrugen ${ }^{1}$ ). Heute, nachdem ich selbst die mit Hülfe meiner Methode ausgeführte Titration des Harns mit Mercurinitrat im Verein mit Dr. Bohland sehr eingehend auf ihren Werth geprïft, bin ich noch mehr als friiher iiberzeugt, dass ich Recht gehabt habe und weder von Gruber, noch von Voit, noch sonst Jemand widerlegt worden bin.

Auf Grund von Versuchen, die Pfeiffer mit Quecksilberlösungen ausführte, „deren Titer", wie er ohne Berechtigung behauptet, „genau nach Pfl üger gestellt war", hat dieser Forscher nun gegen mich verschiedene Ausstellungen zu machen.

Aus den von Pfeiffer in Tabelle I seiner Arbeit mitgetheilten Titrationsversuchen mit $2 \%$ igen Harnstofflösungen und den zur Nentralisation angewandten Mengen von Normalsodalösung ergibt sich, dass die benutzte Mereurinitratlösung sehr viel freie Salpetersäure enthält, obwohl ich ausdrücklich bereits in meiner ersten die Harnstoffanalyse behandelnden Abhandlung ${ }^{2}$ ) vorgeschrieben habe, dass diese Lösungen gar keine freie Salpetersäure enthalten sollen. Hier ist, wie ich schon dort (Bd. 21, p. 278 u. folg.) hervorhob, natürlich abgesehen von derjenigen sehr kleinen Menge freier Salpetersäure, welche anch nicht um eine Spur verringert werden kann, ohne dass sich basisches Salz ausscheidet. Ich gebrauche bei Titration von $10 \mathrm{cem} \mathrm{2 \%}$ iger Harnstofflösung nach Zusatz von 19,7 ccm meiner titrirten Quecksilberlösung nur 11,3 ccm Normalsodalösung zur Neutralisation, während Pfeiffer ${ }^{3}$ ) unter denselben Verhältnissen (in seiner Arbeit Serie a in Tabelle I) $13,3 \mathrm{cem}$ nöthig hat. Der zu neutralisirende Säuregehalt ist bei P fe i f f er also um 17,7\% grösser als meine Vorschrift gestattet. In einer besonderen Bemerkung sagt $P$ fe iffer $\mathrm{r}^{4}$, dass seine Quecksilberlösung "etwas" mehr freie Salpetersäure enthalte, wo-

1) E. P flü ger. Dies Archiv, 21, p. 261 etc.

2) E. P f l ü g er. Dies Archiv, Bd. 21, p. 248.

3) Th. Pfeiffer a. a. 0. p. 542.

4) Th. Pfeiffer a. a. 0. p. 542. 
mit er doch seine Behauptung widerlegt, dass der "Titer genau nach Pfl üger gestellt war." -

Bei einer zweiten Quecksilberlösung, mit der seine Versuche der Serie $d$ in Tabelle $I^{1}$ ) angestellt sind, ergibt sich allerdings, dass die Menge von freier Säure meiner Vorschrift gemäss ist. Aber diese Lösung, mit welcher die Versuche der d-Reihe angestellt sind, hatte einen anderen Quecksilbergehalt, als er von mir vorgeschrieben ist. Folglich ist entgegen Pfeiffer's Behauptung auch diese Lösung nicht so hergestellt, wie ich es vorschreibe.

Ebenso hat die Quecksilberlösung, mit der die e-Reibe seiner Versuche (Tabelle I) ausgeführt ist ${ }^{2}$ ), einen durchaus anderen Quecksilbergehalt, als es Liebig's und meiner Vorschrift entspricht. - In Reihe d beanspruchen 10 ecm $2 \%$ ige Ü-lösung nur 19,0 bis 19,8 cem dieser Hg-lösung; in Reibe d $10 \mathrm{~cm} 2 \%$ ige U๋-lösung gar $\mathbf{2 3 , 7}$ ccm Hg-lösung, statt 20 cem Quecksilberlösung in jedem Fall. Da man weiss, wie viel das Resultat durch die Concentration der Lösungen bei der Liebig'schen Methode beeinflusst wird, so ist es schwer begreiflich, wie Einer, der über den Werth der Methode arbeiten und urtheilen will, die absolut nothwendigsten Voraussetzungen und Vorschriften durchaus vernachlässigen kann.

Nachdem Pfeiffer eigentlich selbst eingestanden, dass seine Lösungen zu viel freie Salpetersäure enthielten und mehrfach einen ganz andern Titer besassen, obwohl er vorher hervorgehoben, dass die Titer , genau nach Pfl ü ge r" gestellt seien, geht er dann dazu über zu beweisen, dass bei der Pfl ïg e r'schen Methode ein höherer Säuregehalt von wesentlichem Einfiuss auf das analytische Resultat ist.

Pfeiffer ${ }^{3}$ ) sagt:

„Beim Rautenberg'schen Verfahren bleibt also in der That. ein höherer Säuregehalt der Quecksilberlösung auf die Harnstoffbestimmung ohne wesentlichen Einfluss, wogegen ein solcher bei der Pflüger'schen Methode deutlich hervortritt."

Pfeiffer hat also eingeseben, dass der Säuregrad meiner titrirten Quecksilberlösung von wesentlichem Einfluss auf das Re-

1) Th. P feiffer a. a. O. p. 542.

2) Th. Pfeiffer a. a. 0. p. 542.

3) Th. Pfeiffer a. a. 0. p. 545 . 
sultat ist, arbeitet aber gleichwohl mit einem anderen Säuregrad, als ich ihn vorschreibe und macht trotzdem die erhaltenen Ungenauigkeiten dann meiner Methode zum Vorwurf.

Denn er sagt (a. a. 0. p. 549):

„Bei meinen nach $\mathrm{Pfl}$ üger gemachten Titrationen lieferte seine Correction auch nicht immer genane Resultate."

Kann das denn nicht durch die zu grosse Menge der freien Säure bedingt sein? Also nur der fehlerhaften Anwendung meiner Methode zur Last fallen?

An einer anderen Stelle hat Pfeiffer nicht im Gedächtniss, was er hier meiner Correction vorwirft. Denn Pfeiffer (a. a. O. p. 547) sagt nun:

"Infolge dessen enthalten einige Lösungen (z. B. die für Serie a "Tabelle I benutzte) etwas mehr freie Salpetersäure, indessen „nur in so geringer Menge, dass sie ohne wahrnehmbaren Ein. "fluss auch bei dem Pfl üg e r'schen Verfahren geblieben ist."

Bei der Erwähnung meiner Correctionsformel mag dann noch ein Tadel besprochen werden, der zuerst von Max Gruber ausging, aber mir so unwesentlich schien, dass ich nicht darauf antwortete. P feiffer bringt diesen Tadel an mehreren Stellen wieder vor.

„Der von Gruber hiergegen (P flüger's Correctionsformel) erhobene Einwand", sagt Th. P fe i f f e ${ }^{1}$ ), „dass Pflüger ungleichmässig vorgeht, indem er bei der Titerstellung obige Formel ausser Acht lässt, ist bereits erwähnt." Dieser Gedanke Gruber's gefällt Th. Pfeiffer so ausserordentlich, dass er in einer besonderen Anmerkung (p. 546) nochmals hervorhebt:

„Vgl. in dieser Hinsicht z. B. die Bemerkung von Gruber ,(Zeitschr. f. Biologie Bd. 17. S. 43), dass Pflü ger die Correction „für Verdïnnung mit Sodalösung gerade bei der Titerstellung „nicht anwendet."

Auf diesen Vorwurf erwidere ich:

Thatsache ist es:

$10 \mathrm{ccm} \mathrm{2 \%}$ iger Harnstofflösung brauchen bei meiner Methode $20 \mathrm{cem}$ der Liebig'schen Quecksilberlösung; also ist $1 \mathrm{cem} \mathrm{Hg}$ lösung $=0,010 \mathrm{gr}$ Harnstoff. Sobald 1 Volum Harnstoffhaltiger Flüssigkeit bei meiner Methode 2 Volumina Liebig'scher Queck-

1) Th. Pfeif fer a. a. 0. p. 549. 
silberlösung braucht, ist die Harnstofflösung sicher $2 \%$ ig. Die auszuführende Correctur ist also $= \pm 0,0$. Weil nun für Harnstofflösungen anderen \%gebaltes $1 \mathrm{ccm}$ der Liebig'schen Lösung nicht mehr $=0,01 \mathrm{gr}$ Harnstoff, war eine Correctionsformel nöthig; und diese musste natürlich bei Anwendung auf $2 \%$ ige Lösungen den zu addirenden Werth $=0$ machen und das leistet meine Formel in der That sehr nahezu.

Meine Correctionsformel ist ${ }^{1}$ ):

„Nennt man das Volum der Harnstofflösung plus dem Volum der Sodalösung, welche zur Neutralisation angewandt, plus dem Volum irgend einer anderen Flüssigkeit, welche frei von Harnstoff hinzugefügt wurde: $V_{1}$ und das Volum der verbranchten Quecksilberlösung $\mathrm{V}_{2}$, so ist die Correctur $\mathrm{C}$

$$
\mathrm{C}=-\left(\mathrm{V}_{1}-\mathrm{V}_{2}\right) \times 0,08^{\prime \prime} \text {. }
$$

Bei Titration von $10 \mathrm{ccm} 2 \%$ Harnstofflösung sind zur Neutralisation von 19,7 ccm Hg-lösung 11,3 ccm Normal-Sodalösung und zur Ausfällung des Harnstoffs und Erzengung des Index 20,0 ecm der Li ebig'schen Quecksilberlösung nothwendig.

Also

$$
\begin{gathered}
\mathrm{V}_{1}=21,3 \\
\mathrm{~V}_{2}=20,0 \\
\mathrm{C}=-(21,3-20) \times 0,08=-0,1 \mathrm{ccm}
\end{gathered}
$$

d. b. die anzuwendende Correctur darf als Null angesehen werden, denn sie fällt in die Beobachtungsfehler; folglich kommt meiner Formel allgemeine Gültigkeit für den Harn in den von mir bezeichneten Grenzen zu. Das ganze Gerede ist schon deshalb ganz gegenstandslos, weil der Titer der Quecksilberlösung von einem Tage zum anderen je nach der Temperatur des Laboratoriums, der Helligkeit und Farbe des Tageslichts sowie der Empfindlichkeit der Retina um $0,1 \mathrm{ccm}$ und mehr $\mathrm{Hg}$-Lösung für $10 \mathrm{ccm} 2 \%$ ige $\stackrel{+}{U}$-lösung schwankt.

Wozu sollte ich also bei der Stellung des Titers eine Correctur anbringen, die praktisch ohne Bedeutung ist?

Es wäre ja übrigens leicht, wenn auch zwecklos, die Correctur bei der Stellung des Titers absolut $=0,000$ zu machen dadurch, dass man die neutralisirende Sodalösung etwas stärker nimmt. $10 \mathrm{ccm}$ dieser müssten $11,3 \mathrm{ccm}$ der Normallösung aequivalent sein.

1) Dies Archiv 21, p. 266. 
Natürlich setzte dies vorans eine Prüfung, ob und um wieviel der Factor 0,08 meiner Correctionsformel zu ändern wäre. Irgend ein Vortheil wird durch das Alles aber nicht erzielt.

Der gesunde Menschenverstand sagt iubrigens Jedem, dass eine empirische Correctionsformel wie die meinige oder die von irgend Jemand absolut strenge and absolut allgemein niemals passt. Ich selbst habe experimentell gezeigt, dass sie bei sehr grossen Verdünnungen und bei höheren Concentrationen im Stiche lässt, aber innerhalb derjenigen Breite der Concentration der Harnstofflösungen, welche beim praktischen Gebrauche gewöhnlich vorkommen und innerhalb der Fehlergrenzen der Methode richtige Werthe liefert. Es wurde bei allen Berechnungen und der experimentellen Begrïndung meiner Correctionsformel stets vorausgesetzt, dass die Quecksilberlösung nach Liebig's Vorsehrift 71,5 gr Quecksilber im Liter enthalte.

Die einzig correcte Erörterung wäre, welcher Fehler bei Titration der Harnlösungen begangen wird, die genau 2\% Harnstoff enthalten, wenn die verbrauchte Anzahl cem Quecksilberlösung nach meiner Formel corrigirt wird, obwohl bei Stellung des Titers die Correction nicht ausgefiuhrt wurde, da der zu addirende Correctionswerth nahezu $=$ Null.

Ich habe zu dem Ende durchstudirt sämmtliche Analysen, welche Dr. B o hland mit Menschen- und Hundeharn ausgeführt hat. Es sind deren 63, und publicirt sind alle für die Berechnung der Correcturen nothwendigen Daten, sodass Jeder mich controliren kann. (S. Bohland. Dies Archiv 35.) - Ebenso sind von mir alle im Bd. 36 dieses Archives publicirten Analysen bearbeitet, welche ich selbst persönlich nach meiner Methode ausgeführt habe; es sind deren 46, sämmtlich mit menschlichem Harne sehr verschiedener Individuen.

Unter diesen 109 nach meiner Methode ausgeftihrten Titrationsanalysen mit Menschen- und Hundeharn kam es nur 2mal vor, dass wirklich $2 \%$ ige Harnstofflösungen titrirt wurden. Es ist dies der Versuch 49 Bohland's im Bd. 35 des Archivs und der Versuch 44 von $\mathrm{Pfl}$ ï ger und $\mathrm{B}$ o h la $\mathrm{nd}$ in Bd. 36. Nimmt man noch die Versuche hinzu, wo die Harnstofflösungen naheza, aber immer kleiner als $2 \%$ ig sind, so finden sich im Ganzen 7 Versuche unter den 109, die wegen des gerügten Fehlers in Frage kommen. Dass so wenige Versuche in Betracht zu ziehen sind, 
liegt daran, dass durch den Zusatz der Barytmischung, der silberlösung und beim Hundeharn der nothwendigen Verdünnung fast alle Harnmischungen weniger als $2 \%$ Harnstoff enthalten.

Um dem Leser einen Einblick in die Grösse des Fehlers, der nun factisch in Folge der Unvollkommenheit der Formel in 7 von 109 Fällen begangen worden ist, zu gewähren, habe ich folgende Tabelle zusammengestellt.

\begin{tabular}{|c|c|c|c|c|c|c|c|c|}
\hline 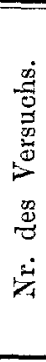 & 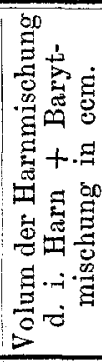 & 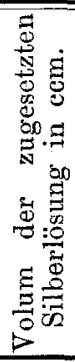 & 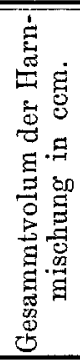 & 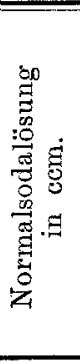 & 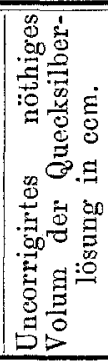 & 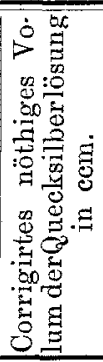 & 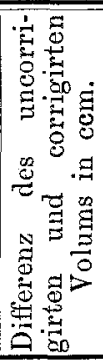 & $\begin{array}{c}\text { Angabe } \\
\text { der Quelle. }\end{array}$ \\
\hline 26 & 12,5 & 0,7 & 13,3 & 14,2 & 25,2 & 25,02 & 0,18 & \multirow{5}{*}{$\begin{array}{c}\text { Bohland. } \\
\text { Dies Archiv, } \\
\text { Bd. } 35, \\
\text { p. } 199 .\end{array}$} \\
\hline 27 & $12, \tilde{5}$ & 0,6 & 13,2 & 14,1 & 25,2 & $2 \tilde{0}, 04$ & 0,16 & \\
\hline 46 & 12,5 & 1,0 & $13, \overline{5}$ & 14,3 & 25,4 & 25,20 & 0,20 & \\
\hline 47 & 12,5 & 0,6 & 13,1 & 14,2 & 25,30 & 25,14 & 0,16 & \\
\hline 49 & 12,5 & 0,4 & 12,9 & 14,5 & 25,90 & 25,80 & 0,10 & \\
\hline 44 & - & - & 21,77 & 23,9 & 41,80 & 41,50 & 0,30 & $\begin{array}{c}\text { Pflüger \& } \\
\text { Bohland. } \\
\text { Dies Archiv, } \\
\text { Bd.36,p.102. }\end{array}$ \\
\hline
\end{tabular}

Wie man sieht ist der eventuelle Fehler, der etwa durch meine Formel bedingt sein könnte, von einerlei Ordnung mit den unvermeidlichen Beobachtungsfehlern. Dabei fragt es sich, ob denn nun, da der Harn neue Complicationen in die aus Lösungen reinen Harnstoffs abgeleiteten Regeln bringt, das Unterlassen der Correctur einen richtigeren Werth erzielt hätte. Nehmen wir zu dem Ende den Versuch, wo die Differenz des corrigirten und uncorrigirten Werthes die maximale je beobachtete Grösse erreicht von $0,3 \mathrm{ecm}$. Der wirkliche Harnstoffgehalt dieses Harns ist anf Grund der nach $\mathrm{Kj}$ el d a h l ausgefuibrten Stickstoffbestimmung $=4,10 \%$ auf Grund des corrigirten Volums der Hg-lösung $=4,149$ " auf Grund des uncorrigirten Volums der Hg-lösung $=4,180$ " 
Man sieht, dass vermöge der durch den Harn bedingten Complication der Erwartung entgegen gerade das corrigirte Volum dem wahren Werthe näher liegt als das nicht corrigirte.

Hiermit dïrften die Tadel von Gruber und Th. P f e if f er ihre Erledigung gefunden haben mit Riicksicht auf die $2 \%$ igen Lösungen.

Schliesslich verweise ich auf meine umfassende mit Dr. Bohland ansgeführte Arbeit, in der an 46 verschiedenen Harnen durch Hunderte von Analysen der Beobachtungsfehler festgestellt ist, der meiner Methode anhaftet. Im Mittel von allen Analysen ergiebt meine Methode den Stickstoff um 0,2\% kleiner als die ganz sichere $\mathrm{Kj}$ e ld a hl 'sche Bestimmung.

Ich habe mit Dr. Bohland alle Daten publicirt, damit Jeder mit Benutzung meiner Correctionsformel den wahren Werth sich selber berechnen könne. Demnach ist meine Methode mit ibrer Formel gegen die Einwendungen jener Forscher sicher gestellt.

Wenden wir uns nunmehr zu den positiven Leistungen, die Dr. Th. Pfeiffer auf Anregung von W. Henneberg zu Tage gefördert hat. Das Wesentliche von Pfeiffer's Methode liegt darin, dass er dem Harn vor Zusatz der Hg-lösung kohlensauren Kalk in so grosser Menge zufügt, dass dieser bis zum Ende der Titration immer in Ueberschusse vorhanden ist. Der Index wird mit Natriumbicarbonat gewonnen.

Pfeiffer's Untersuchung ${ }^{1}$ ) ist auf einen in Princip unrichtigen Gedanken d. h. auf eine Reaction gegründet, die chemisch unmöglich ist. Mangelhafte Ausführung des Experimentes hat dann bewirkt, dass Pfeiffer den inneren Widerspruch seines Verfahrens nicht bemerkte.

Zur specielleren Begrïndung erörtern wir zunächst die Chlorbestimmung.

Bei der Titration des Harnstoffs im natürlichen Harn mit Mercurinitrat wirkt dieses bekanntlich im Anfange auf das Kochsalz, wobei Subliment entsteht, ein im Wasser leicht löslicher, farbloser, den Harnstoff nicht fällender Körper.

$$
\left(\mathrm{NO}_{3}\right)_{2} \mathrm{Hg}+2 \mathrm{CINa}=\mathrm{HgCl}_{2}+2 \mathrm{NO}_{3} \mathrm{Na} \text {. }
$$

Aus diesem Grunde erzeugt Mercurinitrat, wenn es zu Harn gesetzt wird, der am besten ein wenig mit Salpetersäure ange-

1) Zeitschrift für Biologie Bd. XX, p. วّ41. 
säuert ist, im Anfang meist keinen bleibenden Niederschlag, der sich erst einstellt, nachdem eine grössere Menge von Mercurinitrat dem Harne zugesetzt worden ist. Man stellte sich vor, dass dieser Punkt, der durch die entstehende Trubung charakterisirt ist, den Augenblick bezeichnete, in dem alles Kochsalz dureh Mercurinitrat zersetzt sei. Liebig ${ }^{1}$ ) kam zuerst auf den Gedanken, dieses Verhalten von Lösungen, welche Kochsalz und Harnstoff enthalten, auch zur quantitativen Analyse des Kochsalzes zu verwerthen.

Die grösste Vereinfachung dieser Methode haben, wie bereits oben erwähnt, W. Henneberg und F. Rautenberg empfohlen. Man merkt sich im Harn den Punkt, wo Mereurinitrat dauernden Niederschlag macht und zieht das bis dahin verbrauchte Volum Mercurinitratlösung von der gesammten Menge ab, die erforderlich ist, um allen Harnstoff auszufällen. Da die Ausfällung des Harnstoffs an der Anwesenheit freien Mercurinitrates erkannt wird, neben dem aher natïrlich auch Mercurichlorid vorhanden ist, so empfahl Rautenberg mit Natriumbicarbonat den Index zu nehmen, da dies wohl auf das Nitrat, nicht aber auf das Chlorid des Quecksilbers wirkt.

Habel und Fernholz ${ }^{2}$ ) haben, meiner Aufforderung folgend, in einer eingehenden Untersuchung gezeigt, dass die Methode von Henneberg - Rau te n berg unsichere Resultate liefert. Dr. Pfe iffer sieht sich gezwungen auf Grund einer in Henneberg's Laboratorium ausgeführten Arbeit zu erklären ${ }^{3}$ ):

„Bei Harnstoffbestimmungen im menschlichen Harne wollte es dagegen nicht gelingen, mit der Rautenberg'schen Kochsalzcorrection zutreffende Zahlen zu gewinnen; es hat sich daher die von Henneberg in seiner Mittheilung über Rautenberg's Versuche ausgesprochene Vermuthung ${ }^{4}$, dass die Rautenberg'sche

1) J L i e b i g, Ueber einige Harnstoffverbindungen und eine neve Methode z. Bestimmung v. Kochsalz u. Harnstoff im Harn. Annalen. Bd. 85, p. 297.

2) S. Habe 1 und Fernholz. Dies Archiv, 23, 85 und 24, 406.

3) S. Th. P feiffer a. a. 0. p. 558.

4) Was hier Dr. Pfeif f e r eine "Vermuthung" nennt, klingt im Original folgendermaassen: "Versuche mit Harn des Menschen und der Fleisch"fresser liegen zwar bis dahin nicht vor, doch kann es keinem Zweifel unter"liegen, dass die Reaction mit doppelt kohlensaurem Natron sich auch bei "diesen Harnarten bewähren wird. " S. R a u t e n b e r g, Versuche über Harn stoff- und Ammoniakbestimmung im Harn etc., mitgetheilt von W. Henneberg. Liebig's Annalen, B. 133, p. 57. 
Methode ohne Weiteres auch auf menschlichen Harn anwendbar sei, nicht bethätigt.

„In einer Reihe diesbezüglicher Versuche zeigten sich so „widersprechende Umstände, dass auch von einer eventuellen Mo,dification Abstand genommen werden musste.

„In den schwach angesäuerten Harnbarytmischungen trat ,z. B. bisweilen anf Zusatz des ersten Tropfens Quecksilbernitrat „eine Trübung ein, trotzdem grössere Mengen Kochsalz nachweisbar waren etc."

Wenn Th. Pfeiffer zuzugeben gezwangen ist, dass Habel und Fernholz wenigstens für den Harn des Mensehen und der Fleischfresser mit ihrer Einsprache gegen die Methode von Ra utenberg und Henneberg durchaus im Rechte waren; dass also die Behauptung Henneberg's von der Anwendbarkeit dieser Methode auch auf diese Harne auf einem Irrthume, folglich auf falschen Voraussetzungen beruhte, so hätte Dr. P f e iffer, der jetzt auf Veranlassung He n n e b r g's arbeitet, besser die Behauptung unterlassen, dass die von $\mathrm{Habel}$ und Fernhol z gegen die $\mathrm{R}$ a u te n b e r g - H e n n e b e r g'sche Kochsalzcorrection erhobenen Einwände wesentlich auf falschen Voraussetzungen beruhen ${ }^{1}$ ). Denn es ist ja klar, dass diese Behauptung Pfeiffer's sich nur auf Nebensächliches beziehen kann. Für die Analyse des menschlichen Harnes muss also auch nach $P$ feiffer das Chlor mit Silbernitrat ausgefällt werden.

Im Grunde genommen handelt es sich bei RautenbergHenneberg um die Bestimmung des Harnstoff's nach einer vereinfachten Methode. Statt mit Soda, wie Liebig es vorschrieb, neutralisirt Rautenberg die ,beim Entstehen des Harnstoff„Quecksilberoxyds freiwerdende Salpetersäure durch successiven „Zusatz kleiner Mengen von reinem präcipitirtem kohlensauren ,Kalk. Zur Prüfung, ob aller Harnstoff ausgefällt ist, bringt man „,mit dem Glasstabe einen starken Probetropfen auf eine sorgfältig „gereinigte, an der Unterseite dicht mit Asphaltfirniss überzogene „Glasplatte und bedeckt denselben mit einem Tropfen in Wasser „aufgerïhrten doppeltkohlensauren Natrons, wobei das Erscheinen

1) Th. Pfeiffer a. a. O. p. 541. 
„der ersten dentlichen Spuren einer gelben Färbung die Beendi"gung der Reaction anzeigt" 1 ).

Da nun Pfeiffer sich die chemischen Vorgänge nicht klar gemacht hat, so müssen wir zur Beurtheilung seiner Methode auf folgende leicht $\mathrm{zu}$ constatirende und theilweise lüngst bekannte Thatsachen hinweisen.

1) Wenn man zu in Wasser aufgeschwemmtem kohlensauren Kalk ein Paar Tropfen Mercurinitrat fügt, so entsteht sofort eine gelbe Farbe. Es haben also der kohlensaure Kalk und das Mercurinitrat sich theilweise in Calciumnitrat und Quecksilberhydroxyd, resp. basisches Mercurinitrat umgesetzt. $\mathrm{CO}_{3} \mathrm{Ca}$ und $\left(\mathrm{NO}_{3}\right)_{2} \mathrm{Hg}$ können also nicht nebeneinander bestehen, ohne dass sie sich zersetzen unter Abscheidung eines rothen Productes.

2) Wenn kohlensaurer Kalk in einer Harnstofflösung aufgeschwemmt ist und Mercurinitratlösung in nicht zu grosser Menge hinzugefügt .wird, so bleibt die Flïssigkeit, resp. der dünne Brei schneeweiss, selbst wenn der kohlensaure Kalk immer im Ueberschusse vorbanden ist. Daraus folgt, dass das Quecksilber resp. das basische Nitrat desselben jetzt mit dem Harnstoff eine bei neutraler Reaction unlösliche Verbindung eingehet, welche weiss ist. Es kann also jetzt keine rothe Verbindung entstehen.

3) Sobald anf diese Weise nach hinreichendem Zusatz von Mercurinitrat aller Harnstoff gefällt ist und nun noch ein kleiner Ueberschuss von Mercurinitrat zu der Flüssigkeit gefügt wird, so wirkt er sofort auf den im Ueberschusse vorhandenen kohlensauren Kalk. Die bisher schneeweisse Flüssigkeit wird plötzlich rothgelb. Dieser Farbenwechsel markirt sich aber um so undeutlicher, je grösser der Ueberschuss des kohlensauren Kalkes ist, weil die kleinen Mengen des rothen Niederschlags von den grossen des weissen pulverigen kohlensauren Kalkes verdeckt werden. Hat man es nun gar mit Harn zu thun, durch dessen Farbstoff die Flüssigkeit von Anfang an einen gelben Schein annimmt, so wird der Augenblick, wo jener Farbenwechsel auftritt, etwas unsicher zu beobachten.

4) Wenn man in mit Wasser aufgeschlämmten kohlensauren Kalk Salpetersäure in zur Zersetzung des Carbonats unzureichen-

1) Rautenberg, Harnstoff- and Ammoniakbestimmung etc., mitgetheilt von W. Henneberg in Liebig's Annalen, 133, 56. 
der Menge giesst, umschwenkt und mit empfindlichem neutralen Reagenspapier prüft, wird man die Reaction scharf sauer finden - nicht durch die freigewordene Kohlensäure, sondern durch die Salpetersäure, welche noch nicht Zeit gefunden hat, sich mit kohlensaurem Kalk zu sättigen. Man braucht auch das Pulver nach dem Zusatz der Salpetersäure nur zu betrachten, um aus der langen Dauer des Aussprühens der Kohlensäurebläschen von den Kalkcarbonattheilchen sich zu überzengen, dass die Neutralisation Zeit benöthigt, weil eine fast unlösliche Substanz, wie Kalkcarbonat, auf eine lösliche wirken soll. Schüttelt man öfters zur Begünstigung der Ausgleichung die Mischung, so tritt dann alkalische Reaction als Zeichen auf, dass die Neutralisation vollzogen ist. Denn kohlensaurer Kalk reagirt nicht ganz sehwach alkalisch.

Da diese Bemerkung Manchem auffallend sein wird, sei dieselbe näher begründet.

Als ich den mit Wasser aufgeschwemmten kohlensauren Kalk mit recht gutem empfindlichen neutralen Lackmuspapier prïfte, wurde dasselbe zwar nicht sofort aber allmählich bei dauernder Berührung so stark blau, dass ich mich desshalb überzengen wollte, ob Calciumcarbonat in Wasser trotz seiner so geringen Löslichkeit wirklich so stark alkalisch reagire.

Ich pulverisirte Kalkspath und wusch lange mit destillirtem Wasser aus: Reaction wie oben alkaliseh. - Wiederholung des Versuchs mit pulverisirtem weissen Marmor mit ganz demselben Erfolg. - Als ich die Pulver in Wasser aufschwemmte, Kohlensäure durchleitete, abfiltrirte, das Pulver auf dem Filter mit destillirtem Wasser auswusch, und es dann wieder prïfte, war es abermals wie vorher alkalisch. - Gefällt wurde aus einer Lösung von salpetersaurem Kalk mit kleinen Mengen von Sodalösung kohlensaurer Kalk, wobei salpetersaurer Kalk immer im Ueberschuss blieb, abfiltrirt und mit destillirtem Wasser ausgewaschen: das Pulver machte neutrales Lackmuspapier ganz blau. - Ich schwemmte das Pulver in Wasser auf, leitete Kohlensäure durch, filtrirte ab, wusch mit destillirtem Wasser aus : dasselbe Verhalten wie vorher. - Von mir dargestellter oxalsaurer Kalk wurde geglïht, um ihn in kohlensauren zu verwandeln. Ich behandelte diesen mit Kohlensäure, wusch mit destillirtem Wasser aus: das Pulver reagirte alkalisch.

Ich versetzte aufgeschwemmten, nach meiner Ansicht ganz 
reinen kohlensauren Kalk mit grösseren Mengen Salpetersäure, so dass viel Kohlensäure entwich, aber ein Rest von kohlensaurem Kalk blieb, der mit destillirtem Wasser ausgewaschen wurde. Er reagirte alkalisch.

Man kann demnach nicht zweifeln, dass gutes neutrales Reagenspapier durch in Wasser aufgeschwemmtes Pulver von Calciumcarbonat allmählich stark gebläut wird.

Nun pflegen die Chemiker in wässrigen Flüssigkeiten gelöste Säure oft durch überschïssig zugesetzten kohlensauren Kalk zu sättigen und in Anbetracht der geringen Löslichkeit des Kalkcarbonates diese Operation als Neutralisation zu bezeichnen. Ich will in dieser Arbeit den gebräuchlichen Ausdruck beibehalten; wenn ich dann von dem durch kohlensauren Kalk neutralisirten Harn rede, setze ich voraus, dass die Neutralisation durch den Nachweis der eingetretenen Alkalescenz festgestellt ist.

5) Weil nun bei der Titration des Harnstoffs mit Mercurinitrat stets beträchtliche Mengen von Salpetersäure frei werden, so wird es bei Rautenberg's Methode stets eine je nach den Umständen bald längere, bald kürzere Periode geben, in welcher die Flïssigkeit sauer reagirt und unzersetztes Mercurinitrat $\left(\mathrm{Hg}\left(\mathrm{NO}_{3}\right)_{2}\right)$ enthält, obwohl ein Ueberschuss an kohlensaurem Kalk vorhanden ist. Wenn nun die Analytiker, wie es jetzt trotz meiner Warnung Pfeiffer wieder gethan, mit Mercurinitratlösungen arbeiten, welche grössere Mengen freier Salpetersäure enthalten, so wird jene Periode saurer Reaction bedeutend verlängert, wovon ich mich ubberzengt habe. Die Folge ist, dass die Endreaction auf den Index angestellt wird, während die Neutralisation noch lange nicht vollzogen ist.

In der That beweisen die Beschreibungen und Resultate der Versuche, dass Rautenberg und besonders Pfeiffer, welcher als Vorzüge seines Verfahrens der Pfl ïger'schen Methode gegenüber rühmt, „die grösste Sicherheit, dass durch etwaige Verschie"denheiten bei der Neutralisation keine Fehler entstehen" ${ }^{1}$ ), ich sage, die Angaben Pfeiffer's beweisen, dass er meistens mit sauren Harnen gearbeitet hat, weil er versäumte, sich von der Reaction des Harnes zu iiberzengen. Sonst hätte er einsehen müssen, dass die von ihm vorgeschriebene Reaction mit Bicarbonat nur ein-

1) Th. Pfeiffer a. a. 0. p. 546. 
treten kann, wenn die Harnstofflösung sauer ist durch freie Salpetersäure, d. b. wenn die Bedingung eben nicht existirt, welche gerade den Vorzug seiner Methode ausmachen soll.

Ich habe mich bei Harnstofflösungen und Harnen ïberzeugt, dass ausnahmslos die Reaction des Index in der Fliussigkeit selbst zuerst eintritt, wenn Ueberschuss von kohlensaurem Kalk vorhanden ist. Wartet man nach wiederholter Priffung mit gutem neutralem Reagenspapier, bis die Neutralisation stattgefunden hat, d. h. bis das neutrale Lackmuspapier sich bläut und macht nun die Reaction anf den Index mit Bicarbonat, so wird man finden, dass der Harntropfen weiss bleibt, wenn er weiss war oder so gelb, wie er bereits vorher erschien. Es kann ja auch gar nicht anders sein.

Dass Pfeiffer besonders, fast stets bei stark saurer Reaction seines Harns vermuthlich oft nach ungeniugendem Zusatz von Kalkcarbonat gearbeitet hat, geht mit Sicherheit aus folgender Vorschrift desselben hervor:

„10 resp. 15 ce einer Harnstofflösung oder einer L i e b i g„schen Harmbarytmischung (die Kochsalzcorrection soll vorläufig „unberuicksichtigt bleiben) werden in einem Becherglase mit uiber„schïssigem (?) reinem Kalkcarbonat versetzt. Die Quecksilber,lösung lässt man, unter starkem Umrühren mit einem Glasstabe „2von Anfang an, aus der Bürette zufliessen. Während dann die „Endreaction bei reinen Harnstofflösungen sehr scharf schon im „Becherglase selbst eintritt (zur Sicherheit ist jedoch immer die „Natriumbiearbonatprobe gemacht), muss bei den meisten Harnen "die Tüpfelmethode Anwendung finden ${ }^{1}$ ). Zu diesem Zwecke ,waren in bekannter Weise nach und nach immer einige Probe„tropfen auf eine Glasplatte, deren untere Seite mit schwarzem „Asphaltlack überzogen ist, aufgetragen und ein Tropfen aufge"schlemmtes, gereinigtes Natriumbicarbonat hinzugefügt. Der ge,ringste Ueberschuss von Quecksilbernitrat wird so durch den sich

1) Hier sieht er in der Harnstofflösung die wesentiche Reaction, weil der Farbstoff sie nicht verdeckt, was im Harn oft der Fall ist und macht doch die ganz überflüssige Reaction mit Bicarbonat, weil er sich von den Erscheinungen keine genügende Rechenschaft ablegt.

E. PAūger, Archiv f. Physiologie. Bd. XL. 
„scharf abhebenden braunen Ring von ausgeschiedenem basischen "Quecksilbernitrat sicher erkannt" ${ }^{1}$ ).

Wie kann denn ein Ueberschuss von Quecksilbernitrat sein, wenn gleichzeitig ein Ueberschuss von kohlensaurem Kalk in der Flüssigkeit ist und bis zur Sättigung der entstandenen Salpetersäure gewartet wurde?

Dass diese Bemerkung hier am Platze ist, wird durch folgenden Passus des Dr. Th. Pfe iffer ${ }^{2}$ ) sicher gestellt. Er sagt:

„Das Charakteristische der Rautenberg'schen Methode be„steht darin, dass die Neutralisation der zu titrirenden Flüssigkeit „durch successiven Zusatz von kleinen Mengen Kalkearbonat be„,wirkt wird. Selbstverständlich lässt sich aber damit der Neu„tralisationspunkt nicht genau treffen, es wird vielmehr aller "Wahrscheinlichkeit nach stets etwas Kalkcarbonat im Ueberschuss „vorhanden sein, und man arbeitet daber aller Voraussicht nach ,stets in neutral gehaltenen Flüssigkeiten. Für die Riehtig„keit dieser Annahme sprechen auch die Rautenberg'schen „Beleganalysen, in denen eine dem Harne zugesetzte bestimmte "Menge Harnstoff stets richtig wieder gefunden wurde; bei wechseln"der saurer und neutraler Reaction, konnte dies, wie Pfl ü ger ,nachgewiesen hat, nicht der Fall $\left.\operatorname{sein}^{3}\right)$. Um nun aber in dieser "Hinsicht sicher zn gehen, babe ich es vorgezogen, Kalkcarbonat „irn Ueberschuss vor Beginn, der Titration den betreffenden Lösungen „zuzusetzen, wodurch in allen Fällen eine ganz gleichmässige Neu,tralisation der fortwährend frei werdenden Salpetersäure bewirkt ,wird. Während also P flüg er zunächst mit neutralen, dann mit „,fortschreitend sauer werdenden Flüssigkeiten arbeitet und erst „kurz vor Erscheinen der Endreaction neutralisirt, sind bei den ,"vorliegenden Untersuchungen etwaige, aus einem verschiedenen ,Säuregrad erwachsende Fehlerquellen vollständig eliminirt.“

Das ist Alles vollkommen irrig.

Denn es bleibt gewiss, dass wenn der Index so mit Natriumbicarbonat gelingt, wie es Pfeiffer beschreibt, die Flüssigkeit

1) Th. Pfeiffer, a. a. 0. p. 546.

2) Th. Pfeiffer, a. a. 0. p. 541 .

3) Diese Bemerkung ist deshalb nicht zutreffend, weil $R$ a utenberg ja bei der Stellung des Titers ähnlich verfuhr, und der Zufall bei der gar kleinen Zahl von Versuchen seine Hand im Spiele hatte. 
entschieden saner ist. Wie ich mich iiberzeugte, ist es gar nicht leicht, gleich von vorne berein dem Harne so viel Kalkearbonat zuzusetzen, dass am Ende der Titration noch ein Ueberschuss vorhanden ist, der nicht gar zu gross ausfällt und dadurch den Index verwischt. Wie oft glaubte ich nach Zusatz eines Theelöffels Kalkcarbonat genug genommen zu haben und fand bei Prüfung mit Reagenspapier, dass lange vor Beendigung der Titration die gesammte Kalkcarbonatmenge aufgebraucht war und ein neuer Zusatz nothwendig wurde. P f e if f e r hat offenbar diese Prïfung versäumt und fast stets mit unzureichender Kalkmenge gearbeitet, weshalb er auch den Umschlag der Farbe im Harne so oft vermisste.

Dass er nicht selbst die Grube gemerkt hat, in die er fiel, ist um so auffallender, als er in obigem Passus folgendermaassen fortfährt:

„Es sei noch bemerkt, dass jeder Tropfen Quecksilbernitrat ,in mit reinem (nicht harnstoffhaltigem) Wasser aufgeschlemmten ,Kalkearbonat eine Braunfärbung hervorruft, indem die Spuren „,von freier Säure die Umsetzung einleiten" ${ }^{1}$ ).

Demnach muss doch im Harn das überschüssige Kalkearbonat das iiberschiissige Mercurinitrat auch ausfällen, wenn man es nur abwartet, und was soll dann noch das Natriumbicarbonat, da doch dieselbe Arbeit, die es thun kann, schon durch das Calciumcarbonat gethan ist.

Pfeiffer wurde verhindert diesen einfachen Schluss zu machen, weil er offenbar immer sicher zu sein glaubte, dass er genug Kalkcarbonat dem Harne zugesetzt habe, dieser also neutral sein müsse, und fortwäbrend bemerkte, wie der weisse Brei durch Bicarbonat von einer gewissen Periode ab sofort gelbbraun wurde, weil natürlich das in Lösung befindliche Natronsalz viel geschwinder als das ungelöste Kalkcarbonat auf das durch überschüssige Salpetersäure gelöste Mercurinitrat wirkte oder weil vielleicht oft gar kein Kalkcarbonat da war. Pfeiffer merkte das nicht, weil ja auch die Harnstoffquecksilberfällung einen weissen Brei im Becherglas bildet.

Pfeiffer muss sich stillschweigend in die Idee eingelebt

1) Th. Pfeiffer, a. a. 0. p. 546. 
haben, dass im Harn iuberschïssiger kohlensaurer Kalk auf überschüssiges Mercurinitrat nicht einwirke.

Pfeiffer hat also den Index zu einer Zeit genommen, wo neben Mercurinitrat freier Harnstoff existiren konnte, d. h. vor vollendeter Umsetzung. Jeder kann sich hiervon tiberzengen, wenn er wie Pfeiffer verfährt, nach Feststellung des gelben Index mit Bicarbonat aber weiter mit $\mathrm{CO}_{3} \mathrm{Ca}$ versetzt, umschiittelt, die alkalische Reaction abwartet und dann abermals mit Bicarbonat prifft. Die Probe fällt jetzt oft genug weiss aus, sowie auch der Brei im Becherglas weiss ist: also die Titration ist noch nicht zu Ende.

Pfeiffer ist in Folge der Täuschungen ïber seine Neutralisationsmethode so befriedigt, dass er sich zu folgenden Sätzen berechtigt glaubt:

„Als Vorzigge dieser Methode, namentlich dem Pflü ge r'schen „Verfahren gegenüber, ergeben sich aus dem Vorhergehenden:

„1. Grösste Sicherheit, dass dureh etwaige Verschiedenheiten „bei der Neutralisation keine Fehler entstehen ${ }^{1}$ ).

"2. Grösste Einfachheit, indem z. B. die ziemlich umständ„liche genaue Neutralisation mit Sodalösung fortfällt und ferner „ein etwas höherer Gehalt der Quecksilberlösung an freier Sal,petersäure keinen störenden Einfluss ausübt.

,3. Die durch Verdünnung mit Sodalösung entstehenden "Complicationen werden vollständig vermieden" 2).

Pfeiffer wurde in seinen Irrthumern noch weiter dadurch bestärkt, dass er die Richtigkeit seiner Methode bewiesen zu haben glaubte, weil er zu dem Harne absichtlich zugefügten Harnstoff von bekanntem Gewichte annähernd quantitativ wieder nachzuweisen vermochte. Hier handelt es sich aber um einen Trugschluss. Die Quecksilberlösung, welche zur Titration des Harnes gebraucht wird, dient theils zur Fällung des Harnstoffs, theils zur Fällung anderer Körper resp. Vereinigung mit denselben. Nennen wir die erstere Menge des Quecksilbers $\mathrm{H}_{1}$, die zweite Q. Wenn nun zu dem Harne eine bekannte Quantität Harnstoff gesetzt wird, welche die Quecksilbermenge $\mathrm{H}_{2}$ an sich beansprucht,

1) Diese Täuschung Pfeiffer's ist dadurch bedingt, dass er nie mit Reagenspapier sich von der Reaction seiner Flüssigkeit überzeugte, die stark sauer war, während er sie für neutral hielt.

2) Die sub 2 und 3 gepriesenen Vorzüge sind nur leider auf den ge. rügten Fundamentalirrthum basirt. 
so muss der Harn jetzt an Quecksilber verbrauchen: $\mathrm{H}_{1}+\mathrm{Q}+\mathrm{H}_{2}$; während vor dem Zusatz der Verbrauch war: $\mathrm{H}_{1}+\mathrm{Q}$.

Da aber $\left(\mathrm{H}_{1}+\mathrm{Q}\right)+\mathrm{H}_{2}-\left(\mathrm{H}_{1}+\mathrm{Q}\right)=\mathrm{H}_{2}$, so versteht sich der Erfolg des Versuchs von selbst und zeigt, dass der ursprüngliche Harnstoff keineswegs richtig bestimmt wurde, da die Gesammtsumme $\left(\mathrm{H}_{1}+\mathrm{Q}\right)$, nicht aber $\mathrm{H}_{1}$ oder $\mathrm{Q}$ einzeln bekannt sind; wohl aber $\mathrm{H}_{1}+\mathrm{Q}=\mathrm{H}_{1}$ in der Annahme lag, obwohl $\mathrm{Q}$ gegen $\mathrm{H}_{1}$ nicht verschwindet.

Auf diese Art hätte Pfeiffer den Harnstoff im Harn quantitativ genau zu finden geglaubt, selbst in dem Fall, wenn gar kein Harnstoff, sondern nur Ammoniak im Harne enthalten gewesen wäre, ein Verhalten, welches ja durch die Harngährung erzielt werden kann.

Aber thatsächlich beweisen die von mir und Bohland ausgeführten Untersuchungen, dass Pfeiffer im Irrthum ist, wenn er den Harnstoff als solchen im Harne mit Mercurinitrat glaubt bestimmen zu können. Denn wir zeigten, dass die Liebig'sche Methode wohl den Gesammtstickstoff, nimmermehr aber den Harnstoff zu ermitteln gestattet. Wir bewiesen, dass ein sehr grosser Theil, bis $16 \%$ des Stickstoffs des Harns, nicht in Harnstoff, wohl aber in Körpern enthalten ist, die durch Mercurinitrat gefällt werden.

Nun ist allerdings P feiffer's resp. Rautenberg's Metbode noch nicht mit der von $\mathrm{Kjeldahl}$ controlirt und demnach vor der Hand eigentlich ganz unbekannt, was sie leisten kann, wenn sie frei von den durch $\mathrm{Pf}$ eiffer eingeführten Fehlern ausgeführt wird.

Es frug sich also, ob bei correcter Ausführung des Grundgedankens von Rauten berg, welche weder bei ihm noch bei $\mathrm{P}$ f e iffer gefunden werden kann, brauchbare Resultate zu erzielen sind.

Die Neutralisation durch im Ueberschuss gleich von Anfang an zugefügtes Kalkcarbonat fand ich nun aber nicht zulässig und zwar aus dem Grunde, weil grösserer Ueberschuss den Index undeutlich macht. Denn es ist dann zuviel weisser Niederschlag im Harn, in dem sich das Bischen Gelbroth des gefällten Quecksilberoxyds versteckt: Deshalb muss man mit neutralem guten Reagenspapier fortwährend proben, ob noch ïberschïssiges Kalkcarbonat da ist und dies nimmt viel Zeit in Anspruch. Denn wenn man die Reaction während des Titrirens oft scharf sauer findet, 
braucht man nur etwas weiter zu schütteln und wieder zu prïfen: das Papier wird blau und so fort. Hätte Pfe iffer davon etwas gemerkt, so wïrde er eingesehen haben, dass sein Verfahren lästig ist, während man bei meiner Methode vorher ganz genau weiss, wieviel Sodalösung zur Neutralisation erfordert wird.

Meine erste Aufgabe musste es sein, den Titer der $R$ a ut e nberg-Pf'e if f e r'schen Quecksilbernitratlösung zu prifen. Da Pfe iffer hier auf den Farbenumschlag in der Flïssigkeit achten musste, war es von vorne herein wahrscheinlich, dass er den Titer annähernd richtig angegeben habe. Ich stellte nach Pfe iffer's Vorschrift eine Lösung von Mereurinitrat her, die $60,186 \mathrm{gr}$ Quecksilber im Liter enthielt. Ich fand, dass $1 \mathrm{ccm}$ $=0,010 \mathrm{gr}$ Harnstoff entspricht, wenn beim Titriren für stets vorhandenen Ueberschuss an Kalkcarbonat gesorgt wird, was dann freilich die periodisch auftretende stark saure Reaction nicht ausschliesst.

Während Dr. Th. P f e if fer an verschiedenen Stellen seines Aufsatzes Ansichten zu widerlegen sucht, die unrichtig sind, die er aber mir ohne Berechtigung zuschreibt, erörtert er bei der Titerstellung gewisse Principien ${ }^{1}$ ), ohne zu sagen, dass sie mir gehören.

Es handelt sich um die Beobachtung, dass der Quecksilberverbranch, resp. seine Beziehung zum Harnstoff von der Art des Verfahrens bei der Titration abhänge; - dass man den Titer nach derselben Methode stellen miisse, welche nachher beim praktischen Gebrauche innegehalten wird; - dass die vielfach früher benutzten Lösungen gar nicht 71,5 gr Quecksilber im Liter enthielten, wie dies L i e bi g's Vorschrift war, und dass man die Abweichung nicht merkte, weil eben der Titer empirisch gestellt worden war a. s. w. - Der Leser erfährt durch P f e if fer in keiner Weise, dass diese Einsicht erst durch mich gewonnen worden ist.

Meine fernere Aufgabe vor eigentlichem Beginn der Arbeit musste darin bestehen, den von Pfeiffer sogenannten „Verdünnungscoefficienten" $\mathrm{zu}$ bestimmen.

Bekanntlich verbraucht dieselbe in wässriger Lösung befindliche Menge Harnstoff je nacb der Concentration dieser Harnstofflösung verschiedene Mengen der titrirten Quecksilberlösung. Es

1) Th. Pfeiffer, a. a. 0. p. 543 . 
muss demnach das verbrauchte Volumen der letzteren eine Correctur erfahren. Zu dem Ende wird nach Pfeiffer der Correctionscoefficient multiplicirt mit der Differenz, welche man erhält, wenn man von dem doppeltem Volum der harnstoffhaltigen Flüssigkeit das Volum der verbrauchten Mercurinitratlösung abzieht. Dies liefert den Correctionswerth, d. h. die Zahl, welche zu addiren oder abzuziehen ist von der Zahl, welche die verbrauchten cem der Quecksilberlösung angibt.

Schon Rautenberg hatte derartige Bestimmungen ausgeführt. Er arbeitete stets mit $15 \mathrm{ccm}$ harnstoffhaltiger Flüssigkeit, welche, wenn sie $2 \%$ ig gewesen wäre, $29,6 \mathrm{~cm}$ seiner titrirten Quecksilberlösung gebraucht hätte und gibt demnach folgende Vorschrift zur Ermittlung der Correctionsformel:

"Aus diesen Bestimmungen folgt, dass für jeden cem Queck„silberlösung, welcher weniger als 29,6 bis zum Eintritt der End„reaction erforderlich, von der im Ganzen verbrauchten Anzahl eem „abzuziehen ist:

$0,08 \mathrm{ccm}$ bei einem Minderverbrauch unter $10 \mathrm{ccm}$

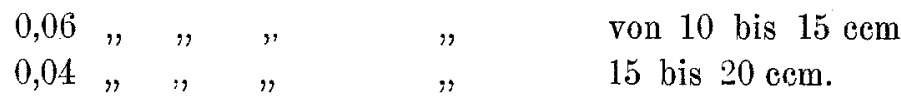

„Wie man sieht, bestätigt sich hier die frïhere Wahrnehmung, dass der Correctionscoefficient mit zunehmender Verdünnung abnimmt" 1 ).

Die Versuche, auf welche gestiitzt Rautenberg seine Regel aufstellt, waren folgende ${ }^{2}$ ):

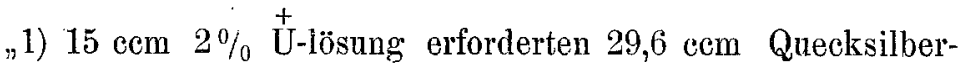
lösung. - Einfach kohlensaures Natron ergab denselben Titer.

2) $10 \mathrm{ccm}$ Harnstoff $+5 \mathrm{ccm}$ Wasser. Quecksilber verbraucht $20,4 \mathrm{eem}$ statt $29,6.2 / 3=19,7$ nach der vorigen Bestimmung; daher Correction für Verdünnung $\frac{20,4-19,7}{29,6-20,4}=0,08 \mathrm{ccm}$ für jedes weniger als 29,6 verbrauchte ecm.

3) $7,5 \mathrm{ccm}$ Harnstoff $+7,5 \mathrm{ccm}$ Wasser. Quecksilber ver. braucht $15,6 \mathrm{cem}$ statt $\frac{29,6}{2}=14,8$. Mithin Correction für Verdünnung 0,06 .

1) Rautenberg Liebig's Annalen 133, p. 58.

2) Li e big's Annalen 133, p. 58. 
4) $5 \mathrm{ccm}$ Harnstoff $+10 \mathrm{~cm}$ Wasser. Quecksilber verbrancht $10 \mathrm{ccm}$ statt 9,$9 ;$ Correction für Verdünnung $=0,04$. (Einfach kohlensaures Natron gab dasselbe Resultat.)"

Da nun Versuch 4 nächst Versuch 3 den wichtigsten Werth liefert und wie der Leser sieht, ein Druckfehler vorliegen muss, so fragt es sich, ob der Verbrauch von $10,0 \mathrm{ccm} \mathrm{Hg}$-lösung, oder der Correctionscoefficient falsch angegeben ist. Weil der Werth 0,04 des Correctionscoefficienten gerade so nochmals in der später anfgestellten Tabelle wiederkehrt, so muss die Zahl 10 falsch sein. Der richtige Werth lässt sich aber folgendermaassen berechnen: $(29,6-9,9-\Delta) \cdot 0,04=\Delta$ :

$$
\begin{aligned}
19,7 \cdot 0,04-\Delta \cdot 0,04 & =\Delta ; \text { also } \\
\frac{19,7 \cdot 0,04}{1,04} & =\Delta \\
0,758 & =\Delta .
\end{aligned}
$$

Verbrauch demnach $9,9+0,758=10,758 \mathrm{ccm} \mathrm{Hg}$-lösung.

Anders ausgedrückt ist der Coefficient:

für eine $1,33 \%$ ige Lösung von Harnstoff $=0,08$;

lösung $=" 10,46 \mathrm{Hg}$-lösung;

" $\quad 1,0, \quad " \quad " \quad=0,06 ; 10 \mathrm{~cm} \stackrel{+}{\mathrm{U}}-$

fitr eine $0,666 \%$ ige Lösung von Harnstoff $=0,04 ; 10 \mathrm{ccm} \stackrel{+}{\mathrm{U}}$ lösung $=7,17 \mathrm{Hg}$-lösung.

Also innerhalb des analytisch wichtigsten Intervalles findet sich für eine Steigernng der Lösung von $0,666 \% \stackrel{+}{\mathrm{U}}$ bis $1 \% \stackrel{+}{\mathrm{U}}$ für je $0,1 \% \stackrel{+}{\mathrm{U}}$ eine Zunahme des $\mathrm{Hg}$-verbrauchs von $0,97 \mathrm{ccm}$, bei Titration von $10 \mathrm{ccm} \stackrel{+}{\mathrm{U}}$-lösung.

Auch frühere Versuche von Henneberg, Stohmann und Rautenberg fuihrten zu dem Ergebniss, dass der Verdiunnungscoefficient mit zunehmender Verdiinnung der Harnstofflösung abnimmt ${ }^{1}$ ).

Um so auffallender ist es, dass Dr. Th. Pfeiffer den Coefficienten von der Verdïnnung unabhängig und constant zu 0,03 für seine Quecksilberlösung findet.

Es ist um so auffallender, als meine Nachuntersuchung er-

1) Henneberg, Stohmann, Rautenberg, Untersuchung des Harns der Pflanzenfresser. Liebig's Annalen 124, p. 191. 
geben hat, dass der Coefficient mit der Verdünnung abnimmt, ganz so wie es Rautenberg, Henneberg, Stobmann behaupteten. Meine Quecksilberlösung hatte aber denselben Quecksilbergehalt, den $P$ feiffer vorschreibt, so dass die Frage entsteht, warum Pfeiffer ein so durchaus anderes Gesetz für den Verdünunngscoefficienten findet als alle anderen Beobachter. Da man es bei den Versuchen uur mit Mercurinitrat und Harnstoff von gegebener Concentration der Lösung zu thun hat, so kann der einzige Unterschied der Versuchsbedingungen in einem verschiedenen Gehalt an freier Salpetersäure in der Quecksilberlösung liegen. Weil aber bei diesen Versuchen durch vorherigen Zusatz von Kalkcarbonat zu der Harnstofflösung die freie Salpetersäuce stets weggenommen wird, ist scbwer zu begreifen, wie sie die Ursache sein sollte, dass Pfeiffer so ganz abweichende Resultate erhalten hat.

Um mir ein Urtheil über seine Bestimmungen des Verdünnungscoefficienten zu ermöglichen, habe ich für seine sämmtlichen Versuche diesen ausgerechuet, weil $\mathrm{Th}$. $\mathrm{P}$ feiffer es unterlassen bat. Er probixt nur, ob er desn gesuchten Werthe näher kommt, wenn er einmal den Coefficienten $=0,04$, das andere $\mathrm{Mal}=$ 0,03 setzt.

Berechuung der Verdünnungscoefficienten nacb Th. Pfeiffer's Tabelie III (a. a. O. p. 549).

Damit der Leser in der Lage sei, meine Rechnung sofort controliren zu können, gebe ich $P$ feiffer's Tabelle III wieder mit der Bemerkung, dass $\mathrm{H}$ bei ihm Harnstofflösung; $\mathrm{Hg}=$ Quecksilbernitratlösung; $W=$ Wasser.

Pfeiffer's Tabelle Ill.

\begin{tabular}{|c|c|c|c|c|c|}
\hline $\begin{array}{c}\text { Zur Titration verwandt } \\
\text { cem. }\end{array}$ & \multicolumn{2}{|c|}{\begin{tabular}{|c|c|} 
Verbraucht Quecksilbernitrat \\
ccm. & $\begin{array}{c}\text { im } \\
\text { Mittel } \\
\text { ccm. }\end{array}$ \\
\end{tabular}} & \multicolumn{2}{|c|}{$\begin{array}{l}\text { Umgerechnet } \\
\text { Verdünnungs- } \\
\text { coefficient } \\
0,04 \mid 0,03 \\
\end{array}$} & \multirow{2}{*}{ 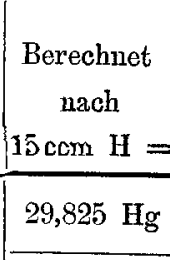 } \\
\hline Erste Lösung: $\begin{aligned} 10 \mathrm{ccm} \\
15 \mathrm{ccm}\end{aligned}$ & $\begin{array}{l}=19,825 \mathrm{ccm} \mathrm{Hg}(19 \\
=29,825 \mathrm{ccm} \mathrm{Hg}(29\end{array}$ & 88.10 & & & \\
\hline 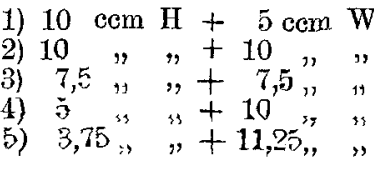 & $\begin{array}{r}20,1 ; 20,0 ; 20,1 ; 20,1 \\
20,3 ; 20,3 ; 20,3 ; 20,3 \\
15,3 ; 15,3 ; 15,2 ; 15,2 \\
10,7 ; 10,7 ; 10,7 ; 10,7 \\
7,9 ; 8,1 ; 8,0 ; 8,1\end{array}$ & $\left|\begin{array}{l}20,075 \\
20,3 \\
15,25 \\
10,7 \\
8,025\end{array}\right|$ & $\begin{array}{c}19,678 \\
19,512 \\
14,66 \\
9,928 \\
7,158\end{array}$ & $\begin{array}{r}19,777 \\
19,719 \\
14,808 \\
10,121 \\
7,366\end{array}$ & $\begin{array}{r}19,88 \\
19,88 \\
14,91 \\
9,94 \\
7,45\end{array}$ \\
\hline
\end{tabular}




\begin{tabular}{|c|c|c|c|c|c|}
\hline $\begin{array}{l}\text { Zur Titration verwandt } \\
\text { ccm. }\end{array}$ & \multicolumn{2}{|c|}{\begin{tabular}{|c|c|} 
Verbraucht Quecksilberuitrat \\
& Mittel \\
ccm. & ccm. \\
\end{tabular}} & \multicolumn{2}{|c|}{$\begin{array}{l}\text { Umgerechnet } \\
\text { Verdünnungs- } \\
\text { coefficient } \\
0,04 \mid 0,03\end{array}$} & \multirow{2}{*}{ 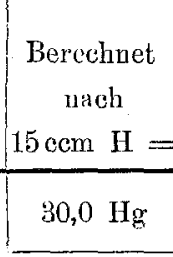 } \\
\hline $\begin{array}{r}\text { weite Lösung (etwas o } \\
15 \mathrm{cem}\end{array}$ & $\begin{array}{l}\text { ydulhaltig) } \\
I=30,0 \mathrm{~cm} \mathrm{H} H\end{array}$ & & & & \\
\hline 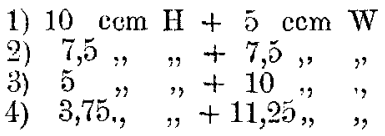 & $\begin{array}{r}20,2,20,3 ; 20,3 \\
15,4 ; 15,4 ; 15,5 \\
10,5 ; 10,5 ; 10,5 \\
8,2 ; 8,2 ; 8,3\end{array}$ & $\begin{array}{c}20,27 \\
15,43 \\
10,5 \\
8,23\end{array}$ & $\begin{array}{l}- \\
- \\
-\end{array}$ & $\begin{array}{c}19,98 \\
14,99 \\
9,9 \\
7,58\end{array}$ & $\begin{array}{r}20,0 \\
15,0 \\
10,0 \\
7,0\end{array}$ \\
\hline 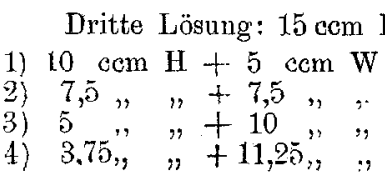 & $\begin{array}{l}\mathrm{H}=30,1 \mathrm{ccm} \mathrm{Hg}(30, \\
20,4 ; 20,4 ; 20,3 ; 20,3 \\
15,3 ; 15,5 ; 15,5 ; \\
10,7 ; 10,7 ; 10,6 ; \\
8,3 ; 8,4 ; 8,3 ; 8,4\end{array}$ & $\begin{array}{l}20,35 \\
15,5 \\
10,63 \\
8,35\end{array}$ & $\begin{array}{l}\text { 1) } \\
- \\
- \\
-\end{array}$ & $\begin{array}{r}20,06 \\
15,06 \\
10,05 \\
7,70\end{array}$ & $\begin{array}{c}30,1 \mathrm{Hg} \\
20,07 \\
15,05 \\
10,03 \\
7,03\end{array}$ \\
\hline
\end{tabular}

Ich will nun in einer Tabelle ibersichtlich zusammenstellen für die drei eben mitgetheilten Serien die $\%$ gebalte der Harnstofflösungen nebst den ihnen entsprechenden Verdünnungscoefficienten.

\begin{tabular}{|c|c|c|c|c|}
\hline $\mathrm{Nr}$. & $\begin{array}{l}\% \text { gehalt der } \\
\text { Harnstoff- } \\
\text { lösung. }\end{array}$ & $\begin{array}{l}\text { Verdünnungr- } \\
\text { coefficient für } \\
\text { Lösung I. }\end{array}$ & $\begin{array}{l}\text { Verdünnungs- } \\
\text { coefficient für } \\
\text { Lösung II. }\end{array}$ & $\begin{array}{l}\text { Verdünnungs- } \\
\text { coefficient für } \\
\text { Lösung III. }\end{array}$ \\
\hline $\begin{array}{l}\text { 1) } \\
\text { 2) } \\
3 \text { ) } \\
\text { 4) } \\
\text { 5) }\end{array}$ & $\begin{array}{l}1,33 \% \\
1,00 \% \\
1,00 \% \\
0,666 \% \\
0,500 \%\end{array}$ & $\begin{array}{l}0,020 \\
0,0 \mathbf{2 2} \\
0,023 \\
0,0397 \\
0,0263\end{array}$ & $\begin{array}{r}0,0277 \\
0,0295 \\
- \\
0,0256 \\
0,0335\end{array}$ & $\begin{array}{c}0,0 \mathbf{8 0} \\
0,0 \mathbf{3 0} \\
-\overline{0 \mathbf{3 0}} \\
0,0 \mathbf{8 8}\end{array}$ \\
\hline
\end{tabular}

Weitere Anhaltspnnkte zur Beurtheilung der Pfe if fer'schen Zahlen werden sich noch aus folgendem Studium derselben ergeben.

Bei der „Ersten Lösung ă 1 und 2 wächst der Coefficient von 0,020 anf 0,023 , während der Harnstoffgehalt von $1,33 \%$ bis $1,0 \%$ sinkt; gerade so verbält sich Lösung II für diesen Fall, d. h. bei Abnahme der $\stackrel{+}{U}$-lösung von $1,33 \%$ auf $1,0 \%$ wächst der Coefficient von 0,0277 auf 0,0295 . Aber bei Lösung III ist der Coefficient unveränderlich $-0,03$. 
Betrachten wir den Einfluss der Abnahme der Concentration der Harnstofflösung von $1 \%$ auf 0,666 für den Coefficienten. Vergleicht man die Versuchsreihe 2, welche mit der ,Ersten Quecksilberlösung" angestellt wurde, so steigt der Coefficient von 0,022 bis 0,0397. - Betrachten wir aber nun was sich für diese Concentrationsabnahme der Harnstofflösung von $1 \%$ auf $0,666 \%$ bei der Quecksilberlösung II und III herausstellt. Damit alle Möglichkeiten erschöpft werden, ergibt Lösung II eine Abnahme, Lösung III Constanz des Coefficienten. Zunahme, Abnahme, Constanz unter angeblich denselben Versuchsbedingungen! Und die Steigerung von 0,023 bis 0,039 ist bei Lösung I eine sehr bedeutende.

Gehen wir endlich über zur Erörterung des Einflusses, den eine Concentrationsabnahme der Harnstofflösung von $0,666 \%$ auf $0,500 \%$ für den Coefficienten hat, so ergiebt sich für die Quecksilber-Lösung I eine sehr bedeutende Abnahme von 0,0397 auf 0,0265, für die Quecksilberlösung II aber eine Zunahme von 0,0256 auf 0,0335 , und ebenso für Lösung III von 0,030 auf 0,038 .

Wer also einen Blick auf die in Pfeiffer's Tabelle aufgestellten Zahlen wirft und für die drei Quecksilber-Lösungen sich im Geiste die drei Curven des "Verdünnungscoefficienten“ in ihrer Abhängigkeit von der Concentration der Harnstofflösung entwirft, der wird aus der totalen Verschiedenheit dieser Curven den sicheren Sehluss ableiten, dass sie nur das Resultat von Beobachtungsfehlern sein können.

Theil II.

\section{Experimentelle Untersuchung.}

Anfänglich wurde der Index auch mit Bicarbonat genommen, später aber, nachdem sich die vollkommene Nutzlosigkeit dieses Reagens wie a priori erwartet herausgestellt hatte, nur der Farbenumschlag im Becherglas berücksichtigt. 
Die Quecksilberlösung enthält selbstverständlich $60,186 \mathrm{gr}$ Quecksilber in Liter, wie es der Rautenberg'schen Vorschrift gemäss ist. Abgekürzt werde ich diese Rau tenberg'sche Quecksilberlösung deshalb $\mathrm{R}^{\prime}-\mathrm{Hg}$-lösung schreiben.

\section{Bestimmung der Verdünnungscoefficienten für die Rantenberg'sche Quecksilberlösung.}

Serie I. $4 \%$ ige Harnstofflösung. $5 \mathrm{ccm}=0,2 \mathrm{gr}$ Harnstoff.

1) $5 \mathrm{ccm} 4 \%$ ige $\stackrel{+}{U}-10 ̈ s u n g=19,35 \mathrm{cem}$. R'-Hg-lösung

2) " " " $"=19,20 \quad, \quad$,

3) $", \quad " \quad=19,28, ", "$

4) " " " $"=19,28, "$,

5) " " " $"=19,35, "$,

Mittel $=19,29 \mathrm{ccm} \mathrm{R}$-Hg-lösung.

Also Verdünnungscoefficient $=0,076$

und $10 \mathrm{~cm} 4 \%$ ige $\stackrel{+}{\mathrm{U}}$-lösung $=38,58 \mathrm{ccm} \mathrm{R} \mathrm{R}^{\prime}$-Hg-Lösung.

S e r i e II. $3 \%$ ige Harnstofflösung.

$6,66 \mathrm{ccm} 3 \%$ ige $\stackrel{+}{\mathrm{U}}$-lösung. $\quad 6,66 \mathrm{~cm}=0,2 \mathrm{gr}$ Harnstoff.

1) $6,66 \mathrm{cem} 3 \%$ ige $\stackrel{+}{U}-$-lösung $=19,4 \mathrm{cem} \mathrm{R}$ - $\mathrm{Hg}$-lösung

2) " " $"=19,5, "$,

3) $\quad, \quad, \quad=19,62, "$,

4) $", \quad, \quad=19,68, "$,

Mittel $=19,56 \mathrm{ccm} \mathbf{R}^{\prime}-\mathrm{Hg}^{-}$-lösung.

Also Verdïnnungscoefficient $=0,070$

und $10 \mathrm{ccm} 3 \%$ ige $\stackrel{+}{\mathrm{U}}$-lösung $=29,34 \mathrm{ccm} \mathrm{R}^{\prime}-\mathrm{Hg}$-lösung. 
S e r i e III. $1 \%$ ige $\stackrel{+}{\text { U-lösung. }} 20 \mathrm{ccm}=0,2 \mathrm{gr}$ Harnstoff.

1) $20 \mathrm{cem} 1 \%$ ige $\stackrel{+}{\mathrm{U}}$-lösung $=20,90 \mathrm{cem} \mathrm{R}^{\prime}$-Hg-lösung

2)

3) " " "

$$
\begin{aligned}
" & =21,00 " \\
" & =20,86 \quad " \\
\text { Mittel } & =20,92 \mathrm{~cm} \mathrm{R} \mathrm{R}^{\prime} \text {-Hg-lösung. }
\end{aligned}
$$

Also Verdünnungscoefficient $=0,048$

und $10 \mathrm{cem} 1 \%$ ige $\stackrel{+}{\mathrm{U}}-$ lösung $=10,46 \mathrm{cem} \mathrm{R} \mathrm{R}^{\prime}$-Hg-lösung.

Serie IV. $\quad 0,5 \%$ ige $\stackrel{+}{\mathrm{U}}-$ lösung. $40 \mathrm{cem}=0,2 \mathrm{gr}$ Harnstoff.

1) $40 \mathrm{ccm} 0,5 \%$ ige $\stackrel{+}{U}^{+}$-lösung $=22,0 \mathrm{ccm} \mathrm{R} \mathrm{R}^{-}$-Hg-lösung

2) " $" \quad=21,97, \quad$,

3) " , $"=22,05 "$,

Mittel $=22,01 \mathrm{cem} \mathbf{R}^{\prime}-\mathrm{Hg}^{-}$-lösung.

Also Verdünnungscoefficient $=0,035$

und $10 \mathrm{cem} 0,5 \%$ ige $\stackrel{+}{\mathrm{U}}$-lösung $=5,5 \mathrm{cem} \mathrm{R}^{\prime}-\mathrm{Hg}$-lösung.

Tabellarische Uebersicht zur Ausfihrung der wegen der Verdünnung nothwendigen Correctur:

$\%$ gehalt der Harnstofflösung: Correctionscoefficient:

$\begin{array}{rr}4 \% & 0,076 \\ 3 \% & 0,070 \\ 1 \% & 0,048 \\ 0,5 \% & 0,035\end{array}$

Ieh benutzte, was schliesslich auf dasselbe hinauslänft, zur Correctur folgende Tabelle:

$\%$ gehalt der

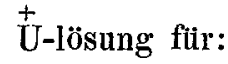

1) $10 \mathrm{cem} 4 \%$

2),$\quad 3 \%$

3) $\quad 1 \%$

4) $, 0,5 \%$
Cem Rautenberg'sehe Quecksilberlösung:

$=38,58 \mathrm{R}$ '-Hg-lösung

$=29,34 \quad$ "

$=10,46 \quad$,

$=5,5 \quad$ 
Hieraus folgt:

Für das Intervall

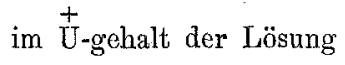
von

$0,5 \%$ bis $1 \%$

$1 \%$ bis $3 \%$

$3 \%$ bis $4 \%$

Mehrverbranch von

$\mathrm{R}^{\prime}$-Hg-Lösung für

jedes $0,1 \% \stackrel{+}{\mathrm{U}}$ mehr

$0,99 \mathrm{ccm}$

$0,94 \quad$ "

0,92 "
Zunahme des

Ũ-gehaltes

$=0,1 \%$

$=0,1 \%$

$=0,1 \%$

\section{Harnversuche.}

\section{Versuch 1 (Harn 1).}

$200 \mathrm{ccm}$ Harn $+100 \mathrm{ccm}$ Liebig'sche Barytmischung.

$10 \mathrm{ccm}$ Harn gebranchen zur Ausfällung des Chlors nach Nohr $7,55 \mathrm{ccm}$ Ag-lösung.

$150 \mathrm{ccm}$ Filtrat der Harnbarytmischung durch 1,5 cem verdünnter Salpetersäure neutralisirt und mit $75,5 \mathrm{ccm} \mathrm{Ag}$-lösung ausgefällt.

Das Filtrat hiervon zur Titration benutzt.

Wegen der Zusammensetzung der Mischung hat man:

$10 \mathrm{ccm}$ Harn $+5 \mathrm{ccm}$ Li ebig'sche Barytmischung $+7,55 \mathrm{ccm} \mathrm{Ag-}$ lösung $+0,15 \mathrm{~cm}$ Salpetersäure $=22,7 \mathrm{ccm}$ Mischung.

A nalyse I. $22,7 \mathrm{ccm}$ Harnmischung $=17,0 \mathrm{~cm}$ Hg-lösung.

$$
\begin{aligned}
& \text { "II. } \quad " \quad=16,7, " \\
& " \text { III. } " \quad " \quad=16,6 " n \\
& \text { Mittel }=16,8 \mathrm{ccm} \cdot \mathrm{Hg} \text {-lösung. }
\end{aligned}
$$

Also $10 \mathrm{ccm}$ Harnmischung $=7,4 \mathrm{ccm}$ Hg-lösung.

$0,99 \mathrm{ccm}$ Hg-lösung: $0,1 \% \stackrel{+}{\mathrm{U}}=(7,4-5,5): 0,192$.

$0,5 \%+0,192 \%=0,692 \% \stackrel{+}{\mathrm{U}}$ in der Mischung.

Weil 22,7 ccm Mischung $=10 \mathrm{ccm}$ Harn, so enthält dieser $1,5708 \%$ Harnstoff oder $0,73419 \%$ Stickstoff.

$5 \mathrm{ccm}$ Harn $=0,05671 \mathrm{gr}$ Stickstoff.

5 ccrn Harn nach Kjeld ahl $=0,03890 \mathrm{gr}$ Stickstoff.

$$
\begin{aligned}
" \quad \text { (Hg-lösung) } & =0,03671 ", " \\
\text { Differenz } & =0,00172 \text { gr Stickstoff. }
\end{aligned}
$$

Fehler der Methode $=-5,7 \%$ des Stickstoffs. 


\section{Versuch 2 (Harn 15).}

200 ecm Harn + 100 ccm Liebig'sche Barytmischung.

$10 \mathrm{ccm}$ Harn gebrauchen zur Ausfällung des Chlors nach Mohr $7,13 \mathrm{ccm} \mathrm{Ag-lösung.}$

$150 \mathrm{ccm}$ Filtrat der Harnbarytmischung durch $1 \mathrm{ccm}$ verdünnter Salpetersäure schwach angesäuert und mit $71,3 \mathrm{ccm} \mathrm{Ag-lösung} \mathrm{ausgefällt.} \mathrm{Mit}$ $\mathrm{CO}_{3} \mathrm{Ca}$ neutralisirt. Erst dann filtrirt. Filtrat zur Titration benutzt.

Gemäss Zusammensetzung der Mischung hat man:

10 cem Harn + 5 ccm Liebig'sche Barytmischung + 0,1 ccm Salpetersäure $+7,13 \mathrm{ccm} \mathrm{Ag-lösung}=22,23 \mathrm{ccm}$ Mischung.

Analyse I. $22,23 \mathrm{ccm}$ Harnmisehung $=16,4 \mathrm{ccm}$ Hg-lösung.

$$
\text { "II. " } \quad \frac{=16,5}{\text { Mittel }=16,45 \mathrm{~cm} \mathrm{Hg-lösung.}}
$$

Also $10 \mathrm{ccm}$ Harnmischung $=7,4 \mathrm{ccm} \mathrm{Hg}$-lösung.

$0,99 \mathrm{ccm}$ Hg-lösung : $0,1 \%=(7,4-5,5): 0,192$.

$0,5 \%+0,192 \%=0,692 \% \stackrel{+}{U}$ in der Mischung.

Weil $22,23 \mathrm{ccm}$ Mischung $=10 \mathrm{~cm}$ Harn, so enthält dieser 1,5383\% Harnstoff oder 0,7190\% Stickstoff.

5 ecm Harn $=0,03595$ gr Stickstoff.

5 ccm Harn nach KjeldahI $=0,03700 \mathrm{gr}$ Stickstoff.

$5 ", \quad$ (Hg-lösung) $=0,03595, "$

Differenz $=0,0010 \sqsubseteq \mathrm{gr}$ Stickstoff.

Fehler der Methode $=-2,8 \%$ des Stickstoffs.

\section{Versuch 3 (Harn 4).}

$200 \mathrm{ccm}$ Harn + $100 \mathrm{ccm}$ Liebig'sche Barytmischung.

$10 \mathrm{ccm}$ Harn gebrauchen zur Ausfällung des Chlors nach Mohr 7,9 ccm Ag-lösung.

$150 \mathrm{ccm}$ Harn durch $1,2 \mathrm{ccm}$ verdünnter Salpetersäure schwach angesäuert, mit $79 \mathrm{ccm} \mathrm{Ag-lösung} \mathrm{ausgefällt,} \mathrm{mit} \mathrm{CO}_{3} \mathrm{Ca}$ neutralisirt und dann filtrirt. Filtrat zur Titration benutzt.

Wegen der Zusammensetzung der Mischung hat man:

$10 \mathrm{ccm}$ Harn + $5 \mathrm{ccm}$ Liebig'sche Barytmischung $+7,9 \mathrm{ccm} \mathrm{Ag-}$ lösung $+0,12 \mathrm{ccm}$ Salpetersäure $=23,02 \mathrm{~cm}$ Mischung.

A nalys I. $23,02 \mathrm{ccm}$ Harnmischung $=15 \mathrm{ccm}$ Hg-lösung.

$$
\begin{aligned}
& \text { "II. } " \quad \text { = } \quad 14,9 " \\
& \text { Mittel }=14,95 \mathrm{ccm} \mathrm{Hg-lösung.}
\end{aligned}
$$

Also $10 \mathrm{ccm}$ Harnmischung $=6,494 \mathrm{ccm}$ Hg-lösung.

$0,99 \mathrm{ccm}$ Hg-lösung : 0,1\% $\stackrel{+}{\mathrm{U}}=(6,494-5,5): 0,1004$.

$0,5 \%+0,1004 \%=0,6004 \% \stackrel{+}{\mathrm{U}}$ in der Mischung. 
Weil 23,02 cem Mischung $=10 \mathrm{ccm}$ Harn, so enthält dieser $1,3821 \%$ Harnstoff oder $0,64599 \%$ Stickstoff.

$5 \mathrm{ccm}$ Harn $=0,32299 \mathrm{gr}$ Stickstoff.

5 com Harn nach $\mathrm{Kjeldahl}=0,03204$ gr Stickstoff.

$$
\text { " " (Hg-lösung) }=\frac{0,03230}{\text { Differenz }}=\frac{0,00026 \mathrm{gr} \text { Stickstoff. }}{}
$$

Fehler der Methode $=+0,8 \%$ des Stickstofts.

\section{Versuch 4 (Harn 4).}

$200 \mathrm{ccm}$ Harn + $100 \mathrm{ccm}$ Li i big'sche Barytmischung.

$10 \mathrm{ccm}$ Harn gebrauchen zur Ausfällung des Chlors nach Mohr $11,35 \mathrm{ccm}$ Ag-lösung.

$150 \mathrm{ccm}$ Harnbarytmischung durch $0,8 \mathrm{ccm}$ verdünnter Salpetersäure schwach angesäuert, mit $113,5 \mathrm{ccm}$ Ag-lösung ausgefällt, mit $\mathrm{CO}_{3} \mathrm{Ca}$ neutralisirt, dann filtrirt und Filtrat zur Titration benutzt.

Wegen der Zusätze zu dem Harne hat man:

$10 \mathrm{ccm}$ Harn + $5 \mathrm{ccm}$ Liebig'sche Barytmischung + 0,08 ccm Salpetersäure $+11,35 \mathrm{ccm}$ Ag-lösung $=26,43 \mathrm{ccm}$ Mischung.

A nalyse I. $26,43 \mathrm{ccm}$ Harnmischung $=23,5 \mathrm{ccm} \mathrm{Hg-lösung.}$

$$
\begin{aligned}
& " \text { II. } \quad " \quad=23,3 " \text { " } \\
& \text { Mittel }=23,4 \mathrm{ccm} \mathrm{Hg} \text {-lösung. }
\end{aligned}
$$

Also $10 \mathrm{ccm}$ Harnmischung $=8,85 \mathrm{ccm}$ Hg-lösung.

$0,99 \mathrm{ccm}$ Hg-lösung : $0,1 \% \stackrel{+}{\mathrm{U}}=(8,85-5,5): 0,338$.

$0,5 \%+0,338 \%=0,838$.

Weil $26,43 \mathrm{~cm}$ Mischung $=10 \mathrm{ccm}$ Harn, so enthält dieser 2,2148\% Harnstoff oder $1,0352 \%$ Stickstoff.

$$
5 \mathrm{com} \mathrm{Harn}=0,05176 \mathrm{gr} \text { Stickstoff. }
$$

อे ccm Harn nach Kjeldahl $=0,05150 \mathrm{gr}$ Stickstoff.

$$
\begin{aligned}
" \quad \text { (Hg-lösung) } & =0,05176, " \\
\text { Differenz } & =0,00026 \mathrm{gr} \text { Stickstoff. }
\end{aligned}
$$

Fehler der Methode $=+0,5 \%$ des Stickstoffs.

$$
\text { Versuch } 5 \text { (Harn 22). }
$$

$200 \mathrm{ccm}$ Harn $+100 \mathrm{ccm}$ Liebig'sche Barytmischung.

$20 \mathrm{ccm}$ Harn gebrauchen zur Ausfällung des Chlors nach $\mathrm{Mohr}$ $21,1 \mathrm{ccm}$ Ag-lösung. Also $10 \mathrm{ccm}=10,55 \mathrm{ccm}$ Silberlösung.

$150 \mathrm{ccm}$ Harnbarytmischung mit $1,2 \mathrm{~cm}$ verdünnter Salpetersäure schwach angesäuert, mit $105,5 \mathrm{ccm}$ Ag-lösung ausgefällt, und noch sauer filtrirt und das Filtrat zur Titration benutzt.

Wegen der Zusätze zu dem Harne hat man:

$10 \mathrm{ccm}$ Harn + $5 \mathrm{ccm}$ Liebig'sche Barytmischung $+0,12 \mathrm{ccm}$ Salpetersäure $+10,55 \mathrm{ccm} \mathrm{Ag}$-lösung $=25,67 \mathrm{ccm}$ Mischung. 
Analyse I. 25,67 ccm Harnmischung $=17,7 \mathrm{~cm}$ Hg-lösung.

$$
\text { "II. " } \quad \begin{array}{cc}
=17,3 & = \\
\text { Mittel } & =17,5 \mathrm{ccm} \text { Hg-lösung. }
\end{array}
$$

Also $10 \mathrm{ccm}$ Harnmischung $=6,82 \mathrm{~cm}$ Hg-lösung.

$0,99 \mathrm{ccm}$ Hg-lösung : $0,1 \% \stackrel{+}{\mathrm{U}}=(6,82-5,5): 0,133$.

$0,5 \%+0,133 \%=0,633 \% \stackrel{+}{\mathrm{U}}$ in der Mischung.

Weil 25,67 ccm Mischung = $10 \mathrm{ccm}$ Harn, so enthält dieser 1,6249\% Harnstoff oder $0,7594 \%$ Stickstoff.

$5 \mathrm{ccm}$ Harn $=0,03797 \mathrm{gr}$ Stickstoff.

$5 \mathrm{ccm}$ Harn nach K jeldahl $=0,03594 \mathrm{gr}$ Stickstoff.

$$
\begin{aligned}
& 5 " \text { "(Hg-lösung) }=0,03797 " \text { " } \\
& \text { Differenz }=\overline{0,00203} \mathrm{gr} \text { Stickstoff. }
\end{aligned}
$$

Fehler der Methode $=+5,6 \%$ des Stickstoffs.

$$
\text { Versuch } 6 \text { (Harn 21). }
$$

$200 \mathrm{ccm}$ Harn + $100 \mathrm{ccm}$ Liebig'sche Barytmischung.

$10 \mathrm{ccm}$ Harn brauchen zur Ausfällung des Chlos nach Mohr $10 \mathrm{ccm}$ Ag-lösung.

$150 \mathrm{ccm}$ Harnbarytmischung durch $1,5 \mathrm{ccm}$ verdünnter Salpetersäure schwach angesäuert, mit $100 \mathrm{ccm}$ Ag-lösung ausgefällt und ohne zu neutralisiren, filtrirt. Filtrat zur Titration gebraucht.

Wegen der zum Harne gemachten Zusätze hat man:

$10 \mathrm{ccm}$ Harn $+5 \mathrm{ccm}$ Liebig'sche Barytmischung $+10 \mathrm{ccm} \mathrm{Ag-}$ lösung $+0,15 \mathrm{~cm}$ Salpetersäure $=25,15 \mathrm{ccm}$ Mischung.

An alyse: $25,15 \mathrm{ccm}$ Harnmischung $=13,0 \mathrm{ccm} \mathrm{Hg}$-lösung.

Also $10 \mathrm{ccm}$ Harnmischung $=5,17 \mathrm{ccm} \mathrm{Hg-lösung.}$

$0,99 \mathrm{ccm}$ Hg-lösung : $0,1 \%=(5,5-5,17): 0,033$.

$0,5 \%-0,033 \%=0,467 \% \stackrel{+}{\mathrm{U}}$ in der Mischung.

Weil $25,15 \mathrm{ccm}$ Mischung $=10 \mathrm{ccm}$ Harn, so enthält dieser $1,1745 \%$ Harnstoff oder $0,54896 \%$ Stickstoff.

$5 \mathrm{ccm}$ Harn $=0,027448 \mathrm{gr}$ Stickstoff.

$5 \mathrm{ccm}$ Harn nach $\mathrm{KjeldahI}=0,02620 \mathrm{gr}$ Stickstoff.

$5 n$ (Hg-lösung) $=0,02745 \%$ "

Differenz $=\overline{0,00125} \mathrm{gr}$ Stickstoff.

Fehler der Methode $=+4,8 \%$ des Stickstoffs.

\section{Versuch 7 (Harn 23).}

$200 \mathrm{~cm}$ Harn + $100 \mathrm{ccm}$ Liebig'sche Barytmisehung.

$20 \mathrm{ccm}$ Harn gebrauchen zur Ausfällung des Chlors nach $\mathrm{M}$ oh r $18,9 \mathrm{ccm}$ Ag-lösung. $10 \mathrm{ccm}=9,45 \mathrm{ccm}$ Ag-lösung. 
$150 \mathrm{com}$ der Harnbarytmischung durch $1,5 \mathrm{~cm}$ verdünnter Salpetersäure schwach angesäuert; mit $94,5 \mathrm{ccm} \mathrm{Ag}$-lösung ausgefällt, mit $\mathrm{CO}_{3} \mathrm{Ca}$ neutralisirt, dann filtrirt und Filtrat zur Titration benutzt.

Wegen der zum Harn gemachten Zusätze hat man:

$10 \mathrm{ccm}$ Harn + $5 \mathrm{ccm}$ Li ebig'sche Barytmischung $+0,15 \mathrm{~cm} \mathrm{Sal-}$ petersäure $+9,45 \mathrm{ccm}$. Ag-lösung $=24,6 \mathrm{ccm}$ Mischung.

A nalyse I. $24,6 \mathrm{~cm}$ Mischung $=17,0 \mathrm{ccm} \mathrm{Hg-lösung.}$

$$
\begin{aligned}
& \text { \# II. } 24,6 n \quad \text { " }=17,0 \text { " } \\
& \text { III. } 24,6, \quad \text { = } \quad 17,0 \text { " }
\end{aligned}
$$

Also $10 \mathrm{ccm}$ Mischung $=6,9 \mathrm{ccm} \mathrm{Hg}$-lösung.

$0,99 \mathrm{ccm} \mathrm{Hg}$-lösung: $0,1 \%=(6,9-5,5): 0,14$.

$0,5 \%+0,14 \%=0,64 \% \stackrel{+}{\mathrm{o}} \%$ in der Mischung.

Weil aber $24,6 \mathrm{~cm}$ Mischung $=10 \mathrm{~cm}$ Harn, so enthält dieser $1,5744 \%$ Harnstoff oder $0,73588 \%$ Stickstoff.

$$
5 \text { ecm Harn }=0,036794 \text {. }
$$

$\overline{5} \mathrm{ccm}$ Harn nach $\mathrm{K}$ jeldahl $=0,034313 \mathrm{gr}$ Stickstoff.

$5 " \#$ (Hg-lösung) =0,036794 " "

$$
\text { Differenz }=\overline{0,002481} \mathrm{gr} \text { Stickstoff. }
$$

Fehler der Methode $=+7,2 \%$ des Stickstoffs.

$$
\text { Versuch } 8 \text { (Harn 18). }
$$

$200 \mathrm{~cm}$ Harn + $100 \mathrm{ccm}$ Li ebig'sche Barytmischung.

$22 \mathrm{ccm}$ Harn gebrauchen zur Ausfällung des Chlors nach Mohr $11 \mathrm{ccm}$ Ag-lösung, also: $10 \mathrm{ccm}$ Harn $=5 \mathrm{ccm}$ Hg-lösung.

$150 \mathrm{ccm}$ Harnbarytmischung durch $1,4 \mathrm{ccm}$ verdünnter Salpetersäure neutralisirt, mit $50 \mathrm{ccm}$ Ag-lösung ausgefällt. Das Filtrat hiervon zur Titration benutzt.

Vermöge der Zusammensetzung der Mischung hat man:

$10 \mathrm{ccm}$ Harn $+5 \mathrm{ccm}$ Liebig'sche Barytmischung + 5 ccm Ag-lösung $+0,14 \mathrm{~cm}$ Salpetersäure $=20,14 \mathrm{ccm}$ Mischung.

A nalyse I. $20,14 \mathrm{ccm}$ Harnmischung $=14,5 \mathrm{ccm}$ Hg-lösung.

$\begin{array}{lllll}\text { II. } 20,14 " & & =14,28 & & \end{array}$

Mittel $=14,46 \mathrm{ccm} \mathrm{Hg}$-lösung.

Also $10 \mathrm{~cm}$ Harnmischung $=7,13 \mathrm{~cm} \mathrm{Hg}$-lösung.

$0,99 \mathrm{ccm}$ Hg-lösung: $0,1 \% \stackrel{+}{\mathrm{U}}=(7,13-5,5): 0,165$.

$0,5 \%+0,165 \%=0,665 \% \stackrel{+}{\mathrm{U}}$ in der Mischung.

Weil 20,14 ccm Mischung $=10 \mathrm{ccm}$ Harn, so enthält dieser $1,3373 \%$ Harmstoff oder $0,6250 \%$ Stickstoff.

$5 \mathrm{ccm}$ Harn $=0,03125 \mathrm{gr}$ Stickstoff,

Die Analyse nach $\mathrm{Kj}$ eldahl mit je 5 ecm Harn. 
Analyse I. Gesammtvorlage $=29 \mathrm{~cm} 1 / 10$ Schwefelsäure. Gebraucht $6,5 \mathrm{ccm} 1 / 10$ Natriumhyposulfitlösung, Gebunden 22,5 ccm 1/10 Schwefelsäure $=0,03159 \mathrm{gr}$ Stickstoff.

A nalyse II. Gesammtvorlage $=29 \mathrm{~cm} 1 / 10$ Schwefelsänre. Gebrancht $6,8 \mathrm{~cm}$ Natriumhyposulfitlösung. Gebunden 22,2 ccm 1/10 Schwefelsäure = 0,0311688 gr Stickstoff.

Analyse I. $5 \mathrm{ccm}$ Harn $=0,031590 \mathrm{gr}$ Stickstoff.

$$
\begin{aligned}
\text { "II. 5 } " ~ & =0,031169 " \eta \quad " \\
\text { Mittel } & =0,031380 \mathrm{gr} \text { Stickstoff. }
\end{aligned}
$$

5 ccm Harn nach $\mathrm{Kjeldahl}=0,031380 \mathrm{gr}$ Stickstoff.

$5 " \quad$ " (Hg-lösung) $=0,031250 " n$

Differenz $=\overline{0,000130} \mathrm{gr}$ Stickstoff.

Fehler der Methode $=-0,4 \%$ des Stickstoffs.

\section{Versuch 9 (Harn 50).}

$200 \mathrm{ccm}$ Harn + $100 \mathrm{ccm}$ Liebig'sche Barytmischung.

$20 \mathrm{ccm}$ Harn gebrauchen nach Mohr $19,3 \mathrm{ccm}$ Ag-lösung, also $10 \mathrm{ccm}$ Harn $=9,65 \mathrm{ccm}$ Ag-lösung.

$150 \mathrm{ccm}$ Filtrat der Harnbarytmischung durch $1,2 \mathrm{ccm}$ verdünnter Salpetersäure neutralisirt, mit $96,5 \mathrm{ccm} \mathrm{Ag-lösung} \mathrm{ausgefällt.} \mathrm{Das} \mathrm{Filtrat} \mathrm{hier-}$ von zur Titration benutzt.

Wegen der Zusammensetzung der Mischung hat man:

$10 \mathrm{ccm}$ Harn + $5 \mathrm{ccm}$ Liebig'sche Barytmischung + 9,65 ccm Aglösung $+0,12 \mathrm{~cm}$ Salpetersäure $=24,77 \mathrm{~cm}$ Mischung.

Analyse I. $24,77 \mathrm{~cm}$ Harnmischung $=18,7 \mathrm{ccm}$ Hg-lösung.

$$
\begin{aligned}
& \text { "II. } 24,77, \quad \# \quad=18,6 " \\
& \text { Mittel }=18,65 \mathrm{ccm} \text { Hg-lösung. }
\end{aligned}
$$

Also $10 \mathrm{ccm}$ Harnmischung $=7,53 \mathrm{ccm} \mathrm{Hg-lösung}$.

$0,99 \mathrm{ccm} H \mathrm{Hg}$-lösung: $0,1 \% \stackrel{+}{\mathrm{U}}=(7,53-5,5): 0,205$.

$0,5 \%+0,203 \%=0,705 \% \stackrel{+}{\mathrm{U}}$ in der Mischung.

Weil 24,77 ccm Mischung $=10 \mathrm{ccm}$ Harn, so enthält dieser $1,7463 \%$ Harnstoff oder $0,8162 \%$ Stickstoff.

$$
5 \mathrm{ccm} \text { Harn }=0,04081 \text { gr Stickstoff. }
$$

Die Analyse nach $\mathrm{Kj}$ eld ahl für $5 \mathrm{com}$ Harn.

Vorlage $=36 \mathrm{ccm} 1 / 10$ Schwefelsäure; gebraucht $8,8 \mathrm{ccm} \mathrm{1/10} \mathrm{Natrium-}$ hyposulfitlösung. Gebunden $27,2 \mathrm{~cm} 1 / 10$ Schwefelsäure $=0,038189 \mathrm{gr}$ Stickstoff.

$5 \mathrm{ccm}$ Harn nach $\mathrm{Kjeldahl}=0,038189 \mathrm{gr}$ Stickstoff.

$$
\begin{aligned}
5 " \# \text { (Hg-lösung) } & =\frac{0,040810}{n} " \\
\text { Differenz } & =0,002621 \mathrm{gr} \text { Stickstoff. }
\end{aligned}
$$

Fehler der Methode $=+6,8 \%$ des Stickstoffs. 


\section{Versuch 10 (Harn 3).}

$200 \mathrm{~cm}$ Harn + $100 \mathrm{ccm}$ Li ebig'sche Barytmischung.

20 ecm Harn gebrauchen zur Ausfällung des Chlors nach Moh r 20,35 ccm Ag-lösung, also $10 \mathrm{~cm}=10,175 \mathrm{~cm} \mathrm{Ag-lösung.}$

$150 \mathrm{ccm}$ Harnbarytmischung durch $1,2 \mathrm{ccm}$ verdünnter Salpetersäure neutralisirt und mit 101,75 ccm Silberlösung ausgefällt. Das Filtrat hiervon zur Titration benutzt.

Wegen der Zusammensetzung der Mischung hat man:

$10 \mathrm{ccm}$ Harn + $5 \mathrm{~cm}$ Liebig'sche Barytmischung $+10,175 \mathrm{ccm} \mathrm{Ag-}$ lösung $+0,12 \mathrm{ccm}$ Salpetersäure $=25,295 \mathrm{ccm}$ Mischung.

Analyse I. $25,295 \mathrm{ccm}$ Harnmischung $=24,45 \mathrm{~cm} \mathrm{Hg-lösung.}$

$$
\text { "II. } 25,295, " \quad=23,75, ",
$$

Mittel $=24,1 \mathrm{ccm}$ Hg-lösung.

Also $10 \mathrm{ccm}$ Harnmischung $=9,53 \mathrm{ccm} \mathrm{Hg}$-lösung.

$0,99 \mathrm{ccm} \mathrm{Hg}-1$ lösung $+0,1 \% \stackrel{+}{\mathrm{U}}=(9,53-5,5): 0,407$.

$0,5 \%+0,407 \%=0,907 \% \stackrel{+}{U}$ in der Mischung.

Weil 25,295 ccm Mischung $=10 \mathrm{ccm}$ Harn, so enthält dieser 2,2942\% Harnstoff $=1,0723 \%$ Stickstoff.

$5 \mathrm{ccm}$ Harn $=0,05361 \mathrm{gr}$ Stickstoff.

Analysen nach Kjeldahl mit je 5 ccm Harn.

Analyse I. Gesammtvorlagen $=43 \mathrm{ccm} 1 / 10$ Schwefelsäure. Gebraucht $6,36 \mathrm{ccm} 1 / 10$ Natriumhyposulfitlösung. Gebunden $36,641 / 10$ Schwefelsäure = $0,05144 \mathrm{gr}$ Stickstoff.

A nalyse II. Gesammtvorlage $=43 \mathrm{~cm} 1 / 10$ Schwefelsäure. Gebraucht $6,96 \mathrm{ccm}$. Gebunden $36,04 \mathrm{ccm} 1 / 10$ Schwefelsäure $=0,05060 \mathrm{gr}$ Stickstoff.

Analyse I $=0,05144 \mathrm{gr}$ Stickstoff.

$$
\begin{aligned}
& " \quad \mathrm{II}=0,05060 ", " \\
& \text { Mittel }=0,05102 \mathrm{gr} \text { Stickstoff. }
\end{aligned}
$$

5 cem Harn nach Kjeldahl $=0,05102$ gr Stickstoff.

$5 "$ " (Hg-lösung) $=0,05361 "$ "

Differenz $=\overline{0,00259} \mathrm{gr}$ Stickstoff.

Fehler der Methode $=+5,1 \%$ des Stickstoffs.

\section{Versuch 11 (Harn 1).}

$150 \mathrm{ccm}$ Harn $+150 \mathrm{ccm}$ Liebig'sche Barytmischung.

$20 \mathrm{ccm}$ Harn gebrauchen zur Ansfällung des Chlors nach Mohr 21,7 ccm Ag-lösung $; 10 \mathrm{ccm}=10,85 \mathrm{ccm}$ Ag-lösung.

$200 \mathrm{ccm}$ Filtrat der Harnbarytmischung durch $5,3 \mathrm{ccm}$ verdünnter Salpetersäure neutralisirt, mit $108,5 \mathrm{~cm}$ Ag-lösung ausgefällt. 
Wegen der Zusammensetzung der Mischung hat man:

$20 \mathrm{ccm}$ Harnbarytmischung $+10,85 \mathrm{~cm} \mathrm{Ag-lösung}+0,53 \mathrm{ccm}$ Salpetersäure $=31,38 \mathrm{ccm}$ Mischung.

Analyse: $31,38 \mathrm{ccm}$ Harnmischung $=20,5 \mathrm{ccm} \mathrm{Hg-lösung.}$

Also $10 \mathrm{ccm}$ Harnmischung $=6,53 \mathrm{ccm} \mathrm{Hg-lösung}$.

$0,99 \mathrm{ccm}$ Hg-lösung : $0,1 \% \stackrel{+}{\mathrm{U}}=(6,53-5,5): 0,104$.

$0,5 \%+0,104 \%=0,604 \%$ Harnstoff in der Mischung.

Weil 31,38 ccm Mischung = $10 \mathrm{ccm}$ Harn, so enthält dieser $1,8953 \%$ Harnstoft oder $0,88586 \%$ Stickstoff.

5 ccm Harn $=0,044293 \mathrm{gr}$ Stickstoff.

Analysen nach Kjeldahl mit je 5 ccm Harn.

Analyse 1. Gesammtvorlagen $=37 \mathrm{~cm} 1 / 10$ Schwefelsäure. Gebraucht $6,3 \mathrm{~cm} 1 / 10$ Natriumhyposulfitlösung. Gebunden $=30,7 \mathrm{ccm} 1 / 10$ Schwefelsäure $=0,04310 \mathrm{gr}$ Stickstoff.

Analyse II. Gesammtvorlagen $=37 \mathrm{ccm} \mathrm{1/10}$ Schwefelsäure. Gebraucht $6,2 \mathrm{ccm} 1 / 10$ Natriumhyposulfitlösung. Gebunden $30,8 \mathrm{ccm} 1 / 10$ Schwefelsäure $=0,04324 \mathrm{gr}$ Stickstoff.

Mittel: $5 \mathrm{ccm}$ Harn $=0,04317 \mathrm{gr}$ Stickstoff.

$5 \mathrm{ccm}$ Harn nach $\mathrm{Kjeldahl}=0,04317 \mathrm{gr}$ Stickstoff.

$5 " \quad$ (Hg-lösung) $=0,04429, \quad$ "

Differenz $=0,00112 \mathrm{gr}$ Stickstoff.

Fehler der Methode $=+2,6 \%$ des Stickstoffs.

\section{Versuch 12 (Harn 3).}

$200 \mathrm{ccm}$ Harn + $100 \mathrm{ccm}$ Liebig'sche Barytmischung.

$20 \mathrm{ccm}$ Harn gebrauchen zur Ausfällung des Chlors nach HabelFernholz 27,4 cem Ag-lösung, also:

$10 \mathrm{ccm}=13,7 \mathrm{~cm} \mathrm{Ag-lösung}$.

$150 \mathrm{ccm}$ Filtrat der Harnbarytmischung durch $1,8 \mathrm{~cm}$ verdünnter Salpetersäure neutralisirt und mit $137 \mathrm{ccm} \mathrm{Ag-lösung} \mathrm{ausgefällt.} \mathrm{Filtrat} \mathrm{hiervon}$ zur Titration benutzt.

Gemäss der Zusammensetzung der Mischung hat man:

$10 \mathrm{ccm}$ Harn $+5 \mathrm{ccm}$ Liebig'sche Barytmischung $+0,18 \mathrm{ccm}$ Salpetersäure $+13,7 \mathrm{~cm} \mathrm{Ag-lösung}=28,88 \mathrm{ccm}$ Harnmischung.

Analyse I. $28,88 \mathrm{~cm}$ Harnmischung $=28 \mathrm{~cm} \mathrm{Hg-lösung.}$

"II. $28,88 " \quad$ " $" 28, "$ Mittel $=28 \mathrm{ccm} \mathrm{Hg-lösung.}$

Also $10 \mathrm{ccm}$ Harnmischung $=9,69 \mathrm{ccm} \mathrm{Hg}$-lösung.

$0,99 \mathrm{ccm} \mathrm{Hg}$-lösung: $0,1 \% \stackrel{+}{\mathrm{U}}=(9,69-5,5) \mathrm{ccm}: 0,42$.

$0,5 \%+0,42 \%=0,92 \%$ U⿺ in der Mischung. 
Weil $28,88 \mathrm{ccm}$ Mischung $=10 \mathrm{ccm}$ Harn, so enthält dieser $2,657 \%$ Harnstoff oder $1,242 \%$ Stickstoff. Also:.

$5 \mathrm{ccm}$ Harn $=0,0621 \mathrm{gr}$ Stickstoff.

Die Analysen von $\mathrm{Kjeldah]} \mathrm{mit} \mathrm{je} 5 \mathrm{ccm}$ Harn.

Analyse I. Gesammtvorlagen $=51 \mathrm{~cm} 1 / 10$ Schwefelsäure.

Gebraucht $7,13 \mathrm{ccm} \mathrm{1/10} \mathrm{Natriumhyposulfitlösung.} \mathrm{Also}$

gebunden $43,87 \mathrm{ccm} \mathrm{1/10}$ Schwefelsäure $=0,06159 \mathrm{gr}$ Stickstoff.

Analyse II. Gesammtvorlagen $=51 \mathrm{ccm} 1 / 10$ Schwefelsäure.

Gebraucht $7,28 \mathrm{~cm} \mathrm{1/10} \mathrm{Natriumhyposulfitlösung.}$

Gebunden $43,72=0,06138 \mathrm{gr}$ Stickstoff.

Analyse I: $5 \mathrm{ccm}$ Harn $=0,06159$ gr Stickstoff.

$"$ II: $5, \quad, \quad=0,06138, \quad "$

Mittel $=0,06148$ gr Stickstoff.

5 ccm Harn nach $\mathrm{Kjeldahl}=0,06148 \mathrm{gr}$ Stickstoff.

$5, "$ (Hg-lösung) $=0,06210, " \quad$, $0,00062 \mathrm{gr}$ Stickstoff.

Fehler der Methode $=+1,0 \%$ des Stickstoffs.

Versuch 13 (Harn 18).

$200 \mathrm{ccm}$ Harn + $100 \mathrm{~cm}$ Liebig'sche Barytmischung.

$20 \mathrm{ccm}$ Harn gebrauchen zur Ausfällung des Chlors nach $\mathrm{Habel-Fern-}$ h o lz 11,52 ccm Ag-lösung, also:

$10 \mathrm{ccm}$ Harn $=5,76 \mathrm{ccm}$ Ag-lösung.

$150 \mathrm{ccm}$ Filtrat der Harnbarytmischung durch $2 \mathrm{~cm}$ verdünnter Salpetersäure neutralisirt und mit $57,6 \mathrm{ccm} \mathrm{Ag-lösung} \mathrm{ausgefällt.} \mathrm{Das} \mathrm{Filtrat}$ hiervon zur Titration benutzt.

Gemäss der Zusammensetzung der Mischung hat man:

$10 \mathrm{ccm}$ Harn $+5 \mathrm{ccm}$ Liebig'sche Barytmischung + 0,2 ccm Salpetersäure $+5,76 \mathrm{ccm} \mathrm{Ag-lösung}=20,96 \mathrm{~cm}$ Harnmischung.

Analyse I: $20,96 \mathrm{~cm}$ Harnmischung $=15,0 \mathrm{~cm}$ Hg-lösung.

" II : $20,96, \quad$ " $, 14,95 \%$ "

Mittel $=14,975 \mathrm{~cm} \mathrm{Hg-lösung.}$

Also $10 \mathrm{ccm}$ Harnmischung $=7,1 \mathrm{ccm} \mathrm{Hg-lösung}$.

$$
\begin{gathered}
0,99 \mathrm{~cm} \text { Hg-lösung: } 0,1 \% \stackrel{+}{\mathrm{U}}=(7,1-5,5): 0,16 . \\
0,5 \%+0,16 \%=0,66 \% \stackrel{+}{\mathrm{U}} \text { in der Mischung. }
\end{gathered}
$$

Weil $20,96 \mathrm{ccm}$ Mischung $=10 \mathrm{ccm}$ Harn, so enthält dieser 1,3834\% Harnstoff oder $0,6466 \%$ Stickstoff.

5 ce Harn $=0,03233 \mathrm{gr}$ Stickstoff.

Die Analyse nach $\mathrm{Kjeldahl}$ mit je 5 ccm Harn.

Analyse I: Gesammtvorlagen $29 \mathrm{ccm} 1 / 10$ Schwefelsäure.

Gebraucht $5,74 \mathrm{~cm}$ Natriumbyposulfitlösung.

Gebunden also $23,26 \mathrm{ccm}^{1} / 10$ Schwefelsäure $=0,03265 \mathrm{gr}$ Stickstoff. 
Ueber die Titration des Harnstoffs mit Mercurinitrat etc.

Analyse II: Gesammtvorlagen $29 \mathrm{~cm} \mathrm{1/10} \mathrm{Schwefelsäure.}$

Gebraucht $5,97 \mathrm{~cm} 1 / 10$ Natriumhyposulfitlösung.

Gebunden also $23,03 \mathrm{ccm} 1 / 10$ Schwefelsäure $=0,03233 \mathrm{gr}$ Stickstoff.

Analyse I: $5 \mathrm{ccm}=0,03265 \mathrm{gr}$ Stickstoff.

, II: $\tilde{5},=0,03233, \quad$,

Mittel $=\overline{0,03249} \mathrm{gr}$ Stickstoff.

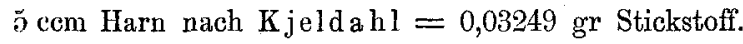

$\check{5}, "(\mathrm{Hg}$-lösung) $=0,03233, "$,

Differenz $=0,00016 \mathrm{gr}$ Stickstoff.

Beobachtungsfehler der Methode $=-0,5 \%$ des Stickstoffs.

Versuch 14 (Harn 25).

$200 \mathrm{~cm}$ Harn + $100 \mathrm{ccm}$ Liebig'sche Barytmischung.

$20 \mathrm{ccm}$ Harn brauchen zur Ausfällung des Chlors nach Habel-Fernhol z 11,1 ccm Ag-lösung, also:

$10 \mathrm{ccm}$ Harn $=5,55 \mathrm{ccm}$ Ag-lösung.

$150 \mathrm{ccm}$ Filtrat der Harnbarytmischung durch $2 \mathrm{~cm}$ verdünnter Salpetersäure neutralisirt, mit $5 \overline{5}, \bar{a} \mathrm{ccm}$ Ag-lösung ausgefällt und das Filtrat hiervon zur Titration benutzt.

Gemäss der Zusammensetzung der Mischung hat man:

$10 \mathrm{ccm}$ Harn $+5 \mathrm{ccm}$ Liebig'sche Barytmischung $+0,2 \mathrm{ccm}$ Salpetersäure $+5,55 \mathrm{ccm} \mathrm{Ag-lösung}=20,75 \mathrm{ccm}$ Mischung.

Analyse I: $20,75 \mathrm{~cm}$ Harnmischung $=20,35 \mathrm{ccm} \mathrm{Hg-lösung}$.

$$
\begin{aligned}
& " \text { II: } 20,75 " \quad " \quad=20,40, \quad, \\
& \text { Mittel }=20,375 \mathrm{ccm} \text { Hg-lösung. }
\end{aligned}
$$

Also:

$10 \mathrm{ccm}$ Mischung $=9,82 \mathrm{ccm} \mathrm{Hg}-$ lösung.

$0,99 \mathrm{ccm}$ Hg-lösung : $0,1 \% \stackrel{+}{\stackrel{U}{U}}=(9,82-5,5) \mathrm{ccm}: 0,44$.

$0,5 \%+0,44 \%=0,94 \% \stackrel{+}{\mathrm{U}}$ in Mischung.

Weil $20,75 \mathrm{ccm}$ Mischung $=10 \mathrm{cc}$ Harn, so enthält dieser $1,9505 \%$ Harnstoff oder $0,9117 \%$ Stickstoff.

$5 \mathrm{ccm}$ Harn $=0,04558 \mathrm{gr}$ Stickstoff.

Die Analyse nach KjeldahI mit je $5 \mathrm{ccm}$ Harn.

Analyse I. Gesammtvorlagen $=45 \mathrm{ccm} 1 / 10$ Schwefelsäure.

Gebraucht 13,28 ccm 1/10 Natriumhyposulfitlösung. Also

gebunden $31,72 \mathrm{ccm} \mathrm{1/10}$ Schwefelsäure $=0,04453 \mathrm{gr}$ Stickstoff.

A nalyse II. Gesammtvorlagen $=45 \mathrm{~cm} 1 / 10$ Schwefelsäure.

Gebraucht 13,21 ccm 1/10 Natriumhyposulfitlösung. Also

gebunden $31,79 \mathrm{ccm} \mathrm{1/10}$ Schwefelsäure $=0,04463 \mathrm{gr}$ Stickstoff.

Mittel $5 \mathrm{ccm}$ Harn $=0,04458 \mathrm{gr}$ Stickstoff. 
$5 \mathrm{com}$ Harn nach Kjeldahl $=0,04458 \mathrm{gr}$ Stickstoff.

5 ccm Harn (Hg-lösung) = 0,04558 " " Differenz $=\overline{0,00100} \mathrm{gr}$ Stickstoff.

Fehler der Methode $=+2,2 \%$ des Stickstoffs.

$$
\text { Versuch } 15 \text { (Harn 1). }
$$

$200 \mathrm{ccm}$ Harn + $100 \mathrm{ccm}$ Li ebig'sche Barytmischung.

$20 \mathrm{ccm}$ Harn gebrauchen zur Ausfällung des Chlors nach $\mathrm{Habe1-}$ Fernholz 14,08 cem Ag-lösung; also:

$10 \mathrm{ccm}$ Harn $=7,04 \mathrm{ccm} \mathrm{Ag-lösung.}$

$150 \mathrm{ccm}$ Filtrat der Harnbarytmischung durch $2 \mathrm{ccm}$ verdünnter Salpetersäure neutralisirt und mit $70,4 \mathrm{ccm}$ Ag-lösung ausgefällt. Das Filtrat hiervon zur Titration benutzt.

Gemäss der Zusammensetzung der Mischung hat man:

$10 \mathrm{ccm}$ Harn + $5 \mathrm{ccm}$ Liebig'sche Barytmischung $+0,2 \mathrm{~cm}$ Salpetersäure $+7,04 \mathrm{ccm} \mathrm{Ag}$-lösung $=22,24 \mathrm{ccm}$ Misehung.

Analyse I. 22,24 ccm Harnmischung $=25,75 \mathrm{ccm}$ Hg-lösung

II. $22,24, \quad " \quad=25,75, \quad$ "

Also: $10 \mathrm{ccm}$ Mischung $=11,58 \mathrm{~cm} \mathrm{Hg-lösung.}$

$0,95 \mathrm{ccm} \mathrm{Hg-lösung:} 0,1 \%=(11,58-10,46): 0,118$.

$0,1 \%+0,118 \%=1,118 \% \stackrel{+}{\mathrm{U}}$ in Mischung.

Weil 22,24 ccm Mischung $=10 \mathrm{ccm}$ Harn, so enthält dieser $2,4864 \%$ Harnstoff oder 1,1622\% Stickstoff.

$5 \mathrm{ccm}$ Harn $=0,0581 \mathrm{gr}$ Stickstoff.

Analyse nach $\mathrm{Kjeldahl}$ mit je $5 \mathrm{ccm}$ Harn:

Analyse. Gesammtvorlagen $=47 \mathrm{~cm} 1 / 10$ Schwefelsäure.

Gebraucht $6,53 \mathrm{ccm} \mathrm{1/10}$ Natriumhyposulfitlösung. Also

gebunden $40,47 \mathrm{ccm} 1 / 10$ Schwefelsäure $=0,05681 \mathrm{gr}$ Stickstoff.

$5 \mathrm{ccm}$ Harn nach Kjeldahl $=0,05681 \mathrm{gr}$ Stickstoff.

$5 \mathrm{ccm}$ Harn (Hg-lösung) = 0,05810 , "

Differenz $=0,00129 \mathrm{gr}$ Stickstoff.

Fehler der Methode $=+2,3 \%$ des Stickstoffs.

Versuch 16 (Harn 24).

$200 \mathrm{ccm}$ Harn + $100 \mathrm{~cm}$ Liebig'sche Barytmischung.

$20 \mathrm{ccm}$ Harn gebrauchen zur Ausfällung des Chlors nach HabeIFernholz 26,85 ccm Ag-lösung; also:

$10 \mathrm{~cm}$ Harn $=13,42 \mathrm{ccm}$ Ag-lösung.

$150 \mathrm{ccm}$ der Harnbarytmischung durch $2 \mathrm{ccm}$ verdünnter Salpetersäure neutralisirt und mit 134,2 ccm Ag-lösung ausgefällt. Das Filtrat hiervon zur Titration benutzt.

Gemäss der Zusammensetzung der Mischung hat man:

$10 \mathrm{ccm}$ Harn $+5 \mathrm{ccm}$ Liebig'sche Barytmischung $+13,42 \mathrm{ccm} \mathrm{Ag}$ lösung $+0,2 \mathrm{ccm}$ Salpetersäure $=28,62 \mathrm{ccm}$ Mischung. 
Ueber die Titration des Harnstoffs mit Mercurinitrat etc.

Analyse I. $28,62 \mathrm{ccm}$ Harnmischung $=17,2 \mathrm{ccm} \mathrm{Hg-lösung}$

$\begin{array}{lrllll}\text { II. } 28,62, & & =17,2, & , \\ \text { " III. } 28,62, & " & =17,2, & , \\ \text { IV. } 28,62, & , & =17,2, & ,\end{array}$

Also: $10 \mathrm{ccm}$ Harnmischung $=6,0 \mathrm{~cm} \mathrm{Hg}$-lösung.

$0,99 \mathrm{ccm}$ Hg-lösung : $0,1 \% \stackrel{+}{\mathrm{U}}=(6,0-5,5) \mathrm{ccm}: 0,05$.

$0,5 \%+0,05 \%=0,55 \% \stackrel{+}{\mathrm{U}}$ in der Mischung.

Weil $28,62 \mathrm{ccm}$ Mischung $=10 \mathrm{ccm}$ Harn, so enthält dieser $1,5741 \%$ Harnstoff oder $0,73573 \%$ Stickstoff.

$5 \mathrm{ccm}$ Harn $=0,036786 \mathrm{gr}$ Stickstoff.

Analyse nach Kjeldahl:

Gesammtvorlagen $=35 \mathrm{ccm} 1 / 10$ Schwefelsäure.

Gebraucht $9,98 \mathrm{ccm} 1 / 10$ Natriumhyposulfitlösung.

Gebunden also $25,02 \mathrm{~cm} \mathrm{1/10} \mathrm{Schwefelsäure}=0,035128 \mathrm{gr}$ Stickstoff.

$5 \mathrm{ccm}$ Harn nach $\mathrm{Kjeldahl}=0,035128$ gr Stickstoff

$5 \mathrm{ccm}$ Harn (Hg-lösung) = 0,036786, ,

Differenz $=0,001658 \mathrm{gr}$ Stickstoff.

Fehler der Methode $=+4,7 \%$ des Stickstoffs.

V ersuch 17 (Harn 1).

$200 \mathrm{ccm}$ Harn + $100 \mathrm{ccm}$ Liebig'sche Barytmischung.

$20 \mathrm{ccm}$ Harn nach Habel-Fernholz zur Ausfällung des Chlors brauchen $18,6 \mathrm{ccm}$ titrirter Silberlösung:

$10 \mathrm{ccm}$ Harn alsn $=9,3 \mathrm{ccm}$ Ag-lösung.

$150 \mathrm{ccm}$ Filtrat der Harnbarytmischung mit $3 \mathrm{ccm}$ verdünnter Salpetersäure neutralisirt, mit $93 \mathrm{ccm} \mathrm{Ag}-$ lösung ausgefällt und Filtrat zur Titration gebraucht.

Gemäss der Zusammensetzung der Mischung hat man:

$10 \mathrm{ccm}$ Harn $+5 \mathrm{~cm}$ Liebig'sche Barytmischung $+0,3 \mathrm{ccm}$ Salpetersäure $+9,3 \mathrm{ccm}$ Ag-lösung $=24,6 \mathrm{ccm}$ Harnmischung.

Analyse 1 ergibt: $24,6 \mathrm{ccm}$ Harnmischung $=20,2 \mathrm{ccm}$ Quecksilberlösung.

Analyse 2 ergibt: $24,6, \quad, \quad=20,4, \quad$,

Mittel : 24,6 ccm Harnmischung $=20,3 \mathrm{ccm}$ Quecksilberlösung.

Also: $10 \mathrm{ccm}$ Harnmischung $=8,25 \mathrm{ccm}$ Quecksilberlösung.

$$
\text { 0,99 ccm Hg-lösung: } \begin{aligned}
0,1 \% \stackrel{+}{\mathrm{U}} & =(8,25-5,5): \mathrm{x} \\
& =2,75: \mathrm{x} \\
0,99: 0,275 & =0,28 .
\end{aligned}
$$

Also: $0,5 \%+0,28 \%=0,78 \% \stackrel{+}{\mathrm{U}}$ in der Mischung.

Weil aber $24,6 \mathrm{ccm}$ Mischung $=10 \mathrm{ccm}$ Harn, so enthält dieser $1,919 \%$ Harnstoff $=0,897 \%$ Stickstoff. 
Die analytischen Belege für die Bestimmung nach $\mathrm{KJeldahl \text {: }}$

Analyse I.

Vorlage $1=40 \mathrm{ccm} \mathrm{1/10} \mathrm{Schwefelsäure.}$

Vorlage $2=1,1 / 10 \quad$,

Gesammtworlage $=41 \mathrm{~cm} 1 / 10$ Schwefelsäure.

Gebraucht $=8,56 \mathrm{~cm}^{1} / 10$ Natriumhyposulfitlösung in toto.

Gebunden $=32,44 \mathrm{ccm} 1 / 10$ Schwefelsäure.

Da $1 \mathrm{ccm} \mathrm{1/10} \mathrm{Schwefelsäure}=0,001404 \mathrm{gr}$ Stickstoff, so sind $\overline{\mathrm{ccm}}$ Harn $=32,44.0,0001404=0,04554 \mathrm{gr}$ Stickstoff.

Analyse II.

Vorlage I u. II (wie bei Analyse I) $=41$ ccm $1 / 10$ Schwefelsäure.

Gebraucht: $=8,4,1 / 10$ Natriumhyposulfitlösung.

Gebunden: $=32,6 \mathrm{ccm} 1 / 0$ Schwefelsäure.

Also: $5 \mathrm{ccm}$ Harn $=0,04577 \mathrm{gr}$ Stickstoff.

Analyse $\mathbf{I}=0,04554 \mathrm{gr}$. Stickstoff.

$$
\begin{aligned}
" \text { II } & =0,04577, " \\
\text { Mittel } & =0,04565 \mathrm{gr} \text { Stickstoff }=5 \mathrm{ccm} \text { Harn. }
\end{aligned}
$$

Die Analyse nach Kjeldahl: $5 \mathrm{ccm}$ Harn $=0,04565 \mathrm{gr}$ Stickstoff.

$$
\text { , " mit Hg-lösung: 5 " " }=0,04485 ", ",
$$

Fehler der Methode $=-1,8 \%$ des Stickstoffs.

$$
\text { Versuch } 18 \text { (Harn II). }
$$

$200 \mathrm{ccm}$ Harn + $100 \mathrm{ccm}$ Liebig'sche Barytmischung.

$20 \mathrm{cem}$ Harn branchen zur Ausfällung des Chlors nach Habel-Fiernholz $18 \mathrm{ccm}$ Ag-lösung.

$10 \mathrm{ccm}$ Harn also $=9,0 \mathrm{ccm}$ Ag-lösung.

$150 \mathrm{ccm}$ Filtrat der Harnbarytmischung mit $2,5 \mathrm{ccm}$ verdünnter Salpetersäure neutralisirt, mit $90 \mathrm{~cm}$ Silberlösung ausgefällt und Filtrat hiervon zur Titration benutzt.

Gemäss der Zusammensetzung der Mischung hat man:

$10 \mathrm{ccm}$ Harn $+5 \mathrm{ccm}$ Liebig'sche Barytmischung $+0,25 \mathrm{ccm}$ verdünnter Salpetersäure $+9 \mathrm{ccm} \mathrm{Ag-lösung}=24,25 \mathrm{ccm}$ Harnmischung.

Analyse 1 gibt: 24,25 ccm Harnmischung $=22,4 \mathrm{ccm}$ Hg-lösung.

$$
\begin{aligned}
2 " 24,25 " \quad & =22,5 " \\
\text { Mittel } & =22,45 \mathrm{cc} \text { Hg-lösung. }
\end{aligned}
$$

Also $10 \mathrm{ccm}$ Harnmischung $=9,26 \mathrm{ccm}$ Quecksilberlösung.

Es ist aber $0,99 \mathrm{ccm}: 0,10_{10}=3,76 \mathrm{ccm}: 0,38 \% ;$ folglich:

$0,5 \%+0,38 \%=0,88 \%$ t

Weil aber $24,25 \mathrm{ccm}$ Mischung $=10 \mathrm{ccm}$ Harn, so enthält dieser $2,134 \%$ Harnstoff $\rightleftharpoons 0,9974 \%$ Stickstoff. 
Ueber die Titration des Harnstoffs mit Mercurinitrat etc.

Die Analyse nach $\mathrm{Kj}$ eldahl mit je $5 \mathrm{ccm}$ Harn.

Analyse I. - Gesammtvorlage $43 \mathrm{~cm} 1 / 10$ Schwefelsäure. Verbraucht $7,13 \mathrm{ccm} \mathrm{1/10} \mathrm{Natriumhyposulfitlösung.} \mathrm{Also} 35,87 \mathrm{ccm} 1 / 10$ Schwefelsäure gebunden $=0,05036 \mathrm{gr}$ Stickstoff $=5 \mathrm{ccm}$ Harn.

A.nalyse II. - Verbraucht $6,94 \mathrm{ccm} 1 / 10$ Natriumhyposulfitlösung. Demnach $36,06 \mathrm{ccm} 1 / 10$ Schwefelsäure gebunden $=0,05063 \mathrm{gr}$ Stickstoff in $5 \mathrm{ccm}$ Harn.

$$
\begin{aligned}
\text { Analyse I: } 5 \mathrm{ccm} \text { Harn } & =0,05036 \text { gr Stickstoff } \\
" \text { II: } " \quad " \quad=0,05063 ", & " \text { MitteI : }=0,05049, "
\end{aligned}
$$

Die Analyse nach $\mathrm{Kjeldahl:} 5 \mathrm{ccm}$ Hara $=0,05049 \mathrm{gr}$ Stickstoff

$$
\begin{aligned}
& \text { " } \quad \text { mit Hg-lösung: } 5, \quad "=0,04987, " \\
& \text { Differenz }=0,00062,
\end{aligned}
$$

Fehler der Methode: $-1,2 \%$ des Stickstoffs.

$$
\text { Versuch } 19 \text { (Harn 18). }
$$

$200 \mathrm{ccm}$ Harn $+100 \mathrm{ccm}$ Liebig'sche Barytmischung.

$20 \mathrm{ccm}$ Harn brauchen zur Ausfällung des Chlors 10,7 ccm Ag-lösung.

Also $10 \mathrm{ccm}$ Harn $=5,35 \mathrm{ccm}$ Ag-lösung.

$150 \mathrm{ccm}$ Filtrat Harnbarytmischung mit $3 \mathrm{ccm}$ verdünnter Salpetersäure neutralisirt, mit $53,5 \mathrm{ccm} \mathrm{Ag-lösung} \mathrm{ausgefällt} \mathrm{und} \mathrm{das} \mathrm{Filtrat} \mathrm{hiervon} \mathrm{zur}$ Titration benutzt.

Gemäss der Zusammensetzung der Mischnng hat man:

$10 \mathrm{ccm}$ Harn $+5 \mathrm{ccm}$ Liebig' scher Barytmischung $+0,3 \mathrm{ccm}$ Salpetersäure $+5,35 \mathrm{ccm}$ Ag-lösung $=20,65 \mathrm{ccm}$ Harnmischung.

Analyse 1: 20,65 ccm Harnmischung $=13,7 \mathrm{ccm} \mathrm{Hg-lösung}$

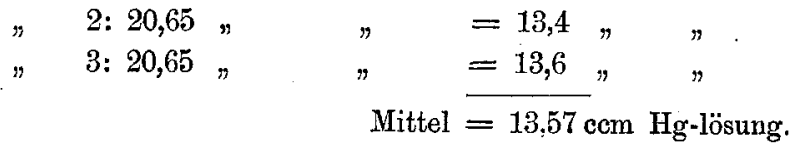

Also: $10 \mathrm{ccm}$ Harnmischung $=6,57 \mathrm{ccm} \mathrm{Hg-lösung.}$ $0,99 \mathrm{ccm}$ Hg-lösung: $0,1 \% \stackrel{+}{\mathrm{U}}=(6,57-5,5): 0,11 \%$ Also: $0,5 \%+0,11 \%=0,61 \stackrel{+}{U}$ in der Mischung.

Weil aber $20,65 \mathrm{ccm}$ Harnmischung $10 \mathrm{ccm}$ Harn enthielten, so beträgt der $\%$ gehalt des Harns

$$
1,260 \% \text { Harnstoff }=0,589 \% \text { Stickstoff. }
$$

Die Analysen nach Kjeldahl mit je $5 \mathrm{ccm}$ Harn.

Analyse I. Gesammtvorlagen $=29 \mathrm{ccm} 1 / 10$ Schwefelsäure.

Gebraucht $8,36 \mathrm{ccm} 1 / 10$ Natriumhyposulfitlösung.

Gebunden $20,64 \mathrm{ccm}$. 1/10 Schwefelsäure $=0,02898 \mathrm{gr}$. Stickstoff.

Analyse II. Gesammtvorlagen $=29 \mathrm{~cm} 1 / 10$ Schwefelsäure.

Gebraucht $8,48 \mathrm{~cm} 1 / 10$ Natriumhyposulfitlösung. 
Gebunden 20.52 $\mathrm{cm} \mathrm{1/10} \mathrm{Schwefelsäure}=0,02881 \mathrm{gr}$ Stickstoff.

Im Mittel gebunden:

$20,58 \mathrm{~cm} \mathrm{1/10} \mathrm{Schwefelsäure}=0,02889 \mathrm{gr}$ Stickstoff $=5 \mathrm{ccm}$ Harn.

כ̌ ccm Harn nach K jeldahl $=0,02889$

$5 \mathrm{ccm}$ Harn (Analyse mit Hg-lösung) $=0,029450$

Differenz $=\overline{0,000560}$

Fehler der Metbode $=+1,6 \%$ des Stickstoffs.

\section{Versuch 20 (Harn 99).}

$200 \mathrm{ccm}$ Harn $+100 \mathrm{ccm}$ Liebig'sche Barytmischung.

20 com Harn brauchen zur Ausfällung des Chlors nach Habel-Fern* holz 23,7 ccm Ag-lösung.

Also: $10 \mathrm{ccm}$ Harn $=11,85 \mathrm{~cm}$ Ag-lösung.

$150 \mathrm{ccm}$ Filtrat neutralisirt durch $3 \mathrm{ccm}$ verdünnter Salpetersäure, ausgefällt mit $118,5 \mathrm{ccm} \mathrm{Ag-lösung} \mathrm{und} \mathrm{das} \mathrm{Filtrat} \mathrm{hiervon} \mathrm{zur} \mathrm{Titration} \mathrm{benutzt.}$

Gemäss der Zusammensetzung der Mischung hat man:

$10 \mathrm{ccm}$ Harn $+5 \mathrm{ccm}$ Li i big'sche Barytmischung $+0,3 \mathrm{ccm}$ Salpetersäure $+11,85 \mathrm{ccm} \mathrm{Ag-lösung}=27,15 \mathrm{ccm}$ Harnmischung.

Analyse 1: $27,15 \mathrm{ccm}$ Harnmischung $=27,8 \mathrm{~cm} \mathrm{Hg}$-lösung.

$$
\begin{aligned}
& \text { "II: } 27,15 " \quad \text { " } \quad=28,2 " \\
& \text { " III: } 27,15, \quad " \quad=28,1 \text { " } \\
& \text { Mittel: }=28,03 \mathrm{ccm} \mathrm{Hg} \text {-lösung. }
\end{aligned}
$$

Also :

$$
\begin{aligned}
10 \mathrm{ccm} \text { Mischung } & =10,32 \mathrm{ccm} \mathrm{Hg} \text {-lösung. } \\
0,99 \mathrm{~cm} \mathrm{Hg}: 0,1 \% & =(10,46-10,32): 0,014 \% .
\end{aligned}
$$

$\mathrm{Da}$ nun $10 \mathrm{ccm} 1 \% \stackrel{+}{\mathrm{U}}$-lösung $=10,46 \mathrm{Hg}$-lösung, so muss diese Mischung: $(1-0,014) \%$ ig sein $=0,986 \%$.

Weil aber $27,15 \mathrm{ccm}$ Harnmischung $=10 \mathrm{ccm}$ Harn, so enthält dieser $2,677 \%$ Harnstoff $=1,251 \%$ Stickstoff.

Die Analysen nach Kjeldahl mit je 5 ecm Harn:

Analyse I. Gesammtvorlagen $=51 \mathrm{ccm} 1 / 10$ Schwefelsäure.

Gebraucht $=6,76 \mathrm{ccm} \mathrm{1/10} \mathrm{Natriumhyposulfitlösung.}$

Gebunden $=44,24 \mathrm{~cm} 1 / 10$ Schwefelsäure.

AnalyseII. Gebraucht $6, \overline{5} \mathrm{~cm} \mathrm{1/10} \mathrm{Natriumhyposulfitlösung.}$

Gebunden 44,50 1/10 Schwefelsäure.

Analyse I: 44,24 ccm 1/10 Schwefelsäure.

, II: 44,50 " "

Mittel: $44,37 \mathrm{ccm} 1 / 10$ Schwefelsäure.

$44,37 \mathrm{cem} 1 / 10$ Schwefelsäure $=0,06230 \mathrm{gr}$ Stickstoff $=5 \mathrm{ccm}$ Harn, 
$5 \mathrm{ccm}$ Harn nach Kjeldahl $=0,06230 \mathrm{gr}$ Stickstoff.

$5 \mathrm{ccm}$ Harn (Analyse mit Hg-lösung) $=0,06255, "$, Differenz $=\overline{0,00025}$ gr Stickstoff.

Fehler der Methode $=+0,4 \%$ des Stickstoffs.

\section{Versuch 21 (Harn III).}

$200 \mathrm{ccm}$ Harn $+100 \mathrm{~cm}$ Li i big'sche Barytmischung.

$20 \mathrm{ccm}$ Harn gebrauchen zur Auställung des Chlors nach Habel-Fernh olz $16 \mathrm{ccm}$ Ag-lösung. Also:

$10 \mathrm{ccm}$ Harn $=8 \mathrm{ccm} \mathrm{Ag-lösung.}$

$150 \mathrm{ccm}$ Filtrat der Harnbarytmischung mit 2,5 cc verdünnter Salpetersäure neutralisirt, mit $80 \mathrm{ccm}$ Silberlösung ausgefällt und das Filtrat hiervon zur Titration gebraucht.

Gemäss der Zusammensetzung der Mischung hat man:

$10 \mathrm{ccm}$ Harn $+5 \mathrm{ccm}$ L i e big'sche Barytmischung $+0,25 \mathrm{~cm}$ Salpetersäure $+8 \mathrm{ccm} A \mathrm{~g}$-lösung $=23,25$ cc Harnmischung.

Analyse I gibt: $23,25 \mathrm{ccm}$ Harnmischung $=18,7 \mathrm{ccm}$ Hg-lösung.

$$
\begin{aligned}
& \text { "II " } 23,25, \quad, \quad=18,5,, \quad \text {, } \\
& \text { Mittel }=18,6 \mathrm{ccm} \text { Hg-lösung. }
\end{aligned}
$$

Also: $10 \mathrm{~cm}$ Harnmisehung $=8,0 \mathrm{~cm}$ Quecksilberlösung.

$$
0,99 \mathrm{ccm}: 0,1 \%=(8-5,5) \mathrm{ccm}: 0,252 \% \text {. }
$$

Also: $0,5 \%+0,25 \%=0,75 \% \stackrel{+}{\mathrm{U}}$ in der Mischung.

Weil aber 23,25 ccm Harnmischung $10 \mathrm{~cm}$ Harn entsprechen, so enthält dieser 1,744\% Harnstoff $=0,815 \%$ Stickstoff.

Die Analysen nach. Kjeldahl mit je $5 \mathrm{ccm}$ Harn:

Analyse I. Gesammtvorlagen $=37 \mathrm{~cm} 1 / 10$ Schwefelsäure.

Gebraucht $=7,27 \mathrm{ccm} \mathrm{1/10} \mathrm{Natriumhyposulfitlösung.}$

Gebunden $=29,73 \mathrm{ccm} 1 / 10$ Schwefelsäure.

Analyse II. Gebrancht $7,43 \mathrm{ccm}$ Natriumhyposulfitlösung.

Gebunden $=29,57 \mathrm{ccm} 1 / 10$ Schwefelsäure.

Analyse I: verbrauchte $1 / 10$ Schwefelsäure $=29,73 \mathrm{ccm}$

$$
\text { , II: } " \quad " \quad \text { " } \quad 29,57 \text {, }
$$

Mittel $=29,65 \mathrm{ccm}$

$29,65 \mathrm{ccm} 1 / 10$ Schwefelsäure $=0,04163 \mathrm{gr}$ Stickstoff $=5 \mathrm{ccm}$ Harn.

Die Analyse nach $\mathrm{Kjeldahl:} 5 \mathrm{ccm}$ Harn $=0,04163 \mathrm{gr}$ Stickstoff.

$$
\text { " } \quad \text { mit Hg-lösung: } 5 \mathrm{ccm},=0,04075, ",
$$

Fehler der Methode $=-2,1 \%$ des Stickstoffs.

Versuch 22 (Harn 5).

$200 \mathrm{ccm}$ Harn + $100 \mathrm{~cm}$ Liebig'sche Barytmischung.

$20 \mathrm{ccm}$ Harn brauchen zur Ausfällung des Chlors nach Habel-Fernholz 21,5 com Silberlösung. 
Also: $10 \mathrm{ccm}$ Harn $=10,75 \mathrm{ccm}$ Ag-lösung.

$150 \mathrm{ccm}$ Filtrat der Harnbarytmischung mit $3 \mathrm{ccm}$ verdünnter Salpetersäure neutralisirt, mit $107,5 \mathrm{~cm} \mathrm{Ag-lösung} \mathrm{ausgefällt} \mathrm{und} \mathrm{Filtrat} \mathrm{hiervon} \mathrm{zur}$ Titration benutzt.

Gemäss der Zusammensetzung der Mischung hat man:

$10 \mathrm{ccm}$ Harn $+5 \mathrm{ccm}$ Barytmischung $+0,3 \mathrm{ccm}$ Salpetersäure $+10,75 \mathrm{ccm}$ $\mathrm{Ag}$ lösung $=26,05 \mathrm{ccm}$ Harnmischung.

Analyse I: $26,05 \mathrm{ccm}$ Harnmischung $=12,70 \mathrm{ccm} \mathrm{Hg}$-lösung.

$$
\text { "II: } 26,05, \quad \text { " } \begin{aligned}
&=12,45, \\
&=12,57 \mathrm{ccm} \\
& \mathrm{Hg} \text {-lösung. }
\end{aligned}
$$

Also: $10 \mathrm{~cm}$ Harnmischung $=4,83 \mathrm{ccm}$ Hg-lösung.

$$
0,99 \mathrm{ccm} \text { Hg-lösung: } 0,1 \% \stackrel{+}{\mathrm{U}}=(5,5-4,8): 0,07 \text {. }
$$

Also: $0, \overline{0}-0,07=0,43 \% \stackrel{+}{\mathrm{U}}$ in der Mischung.

Weil aber $26,05 \mathrm{ccm}$ Harnmischung $=10 \mathrm{ccm}$ Harn, so enthält dieser: $1,120 \%$ Harnstoff $=0,523 \%$ Stickstoff.

Die Analyse nach Kjeldahl mit je $5 \mathrm{ccm}$ Harn.

Analyse 1. Gesammtvorlagen $=27 \mathrm{ccm} 1 / 10$ Schwefelsäure.

Gebraucht $8,35 \mathrm{ccm} 1 / 10$ Natriumhyposulfitlösung.

Gebunden 18,65 ccm 1/10 Schwefelsäure.

Analyse II: Gesammtvorlagen $=27 \mathrm{ccm} 1 / 10$ Schwefelsäure.

Gebraucht $8,11 \mathrm{ccm} 1 / 10$ Natriumhyposulfitlösung.

Gebunden 18,89 ccm 1/10 Schwefelsäure.

Analyse I: $18,65 \mathrm{ccm} 1 / 10$ Schwefelsäure.

$$
\text { "II: } 18,89,1 / 10 \text {, }
$$

Mittel: $18,77 \mathrm{~cm} \mathrm{1/10} \mathrm{Schwefelsäure.}$

$18,77 \mathrm{ccm} 1 / 10$ Schwefelsäure $=0,02635 \mathrm{gr}$ Stickstoff $=5 \mathrm{~cm}$ Harn

Die Analyse nach Kjeldahl $5 \mathrm{ccm}$ Harn $=0,0263 \mathrm{gr}$ Stickstoff.

$$
\text { " " mit Hg-lösung } 5 ", \quad=0,0261 ", " \text { " } "
$$

Fehler der Methode $=-0,8 \%$ des Stickstoffs.

\section{Versuch 23 (Harn 1).}

$200 \mathrm{ccm}$ Harn $+100 \mathrm{ccm}$ Li ebig'sche Barytmischung.

$20 \mathrm{ccm}$ Harn brauchen zur Ausfällung des Chlors nach Habel-Fernholz 11,65 ccm Ag-lösung.

Also: $10 \mathrm{ccm}$ Harn $=5,825 \mathrm{ccm}$ Ag-lösung.

$150 \mathrm{ccm}$ Filtrat mit $3 \mathrm{ccm}$ verdünnter Salpetersäure neutralisirt, mit $58,25 \mathrm{~cm}$ Ag-lösung ausgefällt und das Filtrat hiervon zur Titration benutat.

Gemäss der Zusammensetzung der Mischung hat man:

$10 \mathrm{ccm}$ Harn + $5 \mathrm{ccm}$ Liebig'sche Barytmischung $+5,82 \mathrm{~cm} \mathrm{Ag-}$ lösung $+0,3 \mathrm{ccm}$ Salpetersäure $=21,125 \mathrm{ccm}$ Mischung. 
Analyse 1: 21,125 ccm Harnmischang $=12,4 \mathrm{ccm} \mathrm{Hg}$-lösung.

$$
\begin{aligned}
& \begin{array}{llll} 
& 2: 21,125, & , & =12,25, "
\end{array} \\
& \text { Mittel }=12,33 \mathrm{ccm} \mathrm{Hg} \text {-lösung. }
\end{aligned}
$$

Also: $10 \mathrm{ccm}$ Harnmischung $=5,8 \mathrm{~cm} \mathrm{Hg-lösung}$.

$$
0,99 \mathrm{~cm} \mathrm{Hg}: 0,1 \% \stackrel{+}{\mathrm{U}}=(5,8-\overline{0}, \overline{0}): 0,03 ;
$$

Also: $0,5 \%+0,03 \%=0,53 \%$ für die Mischung.

Da aber $21,125 \mathrm{ccm}$ Mischung $=10 \mathrm{ccm}$ Harn, so enthält dieser $1,1196 \% \stackrel{+}{\mathrm{U}}$ oder $0,5233 \%$ Stickstoff.

$$
5 \mathrm{ccm} \text { Harn }=0,026165 \mathrm{gr} \text { Stickstoff. }
$$

Die Analysen nach Kjeldahl mit je $5 \mathrm{~cm}$ Harn.

Analyse 1: Gesammtvorlage $=25 \mathrm{ccm} 1 / 10$ Schwefelsäure.

Gebraucht $=6,36 \mathrm{ccm} \mathrm{1/10} \mathrm{Natriumhyposulfitlösung.}$

Gebunden $=18,64 \mathrm{~cm} \mathrm{1/10}$ Schwefelsäure $=0,02617 \mathrm{gr}$ Stickstoff.

Analyse II. Gesammtvorlage $=25 \mathrm{~cm} \mathrm{1/10} \mathrm{Schwefelsäure.}$ Gebraucht $=6,19 \mathrm{~cm} 1 / 10$ Natriumhyposulfitlösung.

Gebunden $18,81 \mathrm{ccm}^{1} / 10$ Schwefelsäure $=0,02641 \mathrm{gr}$ Stickstoff. Analyse I: $=0,02617 \mathrm{gr}$ Stickstoff.

" II: $=0,02641$, ,

Mittel $=0,02629 \mathrm{gr}$ Stickstoff $=5 \mathrm{ccm}$ Harn.

$5 \mathrm{cem}$ Harn nach $\mathrm{Kj}$ eldahl $=0,02629$ gr Stickstoff.

$5 \mathrm{ccm}$ Harn (Hg-lösung) = 0,026165, ,

$$
\text { Differenz }=0,000125 \mathrm{gr} \text { Stickstoff. }
$$

Fehler der Methode $=-0,5 \%$ des Stickstoffs.

Versuch 24 (Harn III).

$200 \mathrm{ccm}$ Harn + $100 \mathrm{ccm}$ Liebig'sche Barytmischung.

$20 \mathrm{ccm}$ Harn gebrauchen zur Ausfällung des Chlors nach HabelFernholz 18,8 ccm Ag-lösung.

Also: $10 \mathrm{ccm}$ Harn $=9,4 \mathrm{ccm}$ Ag-lösung.

$150 \mathrm{ccm}$ Filtrat der Harnbarytmischung durch $2 \mathrm{ccm}$ verdünnter Salpetersäure neutralisirt, mit $94 \mathrm{ccm}$ Ag-lösung ausgefällt und das Filtrat hiervon zur Titration benutzt.

Gemäss der Zusammensetzung der Mischung hat man:

$10 \mathrm{~cm}$ Harn + $5 \mathrm{ccm}$ Li ebig' sche Barytmischung + 9,4 ccm Ag-lösung $+0,2 \mathrm{ccm}$ Salpetersäure $=24,6 \mathrm{ccm}$ Harnmischung.

Analyse 1. $24,6 \mathrm{ccm}$ Harnmischung $=24,4 \mathrm{~cm} \mathrm{Hg-lösung}$

$$
\begin{aligned}
& \text { 2. } 24,6, \quad " \quad=24,35, \quad " \\
& \text { "3. } 24,6 " \quad " \quad=24,50 " \text { " } \\
& " \text { 4. } 24,6 " \text { " } "=24,50 " \text { " } \\
& \text { Mittel }=24,44 \mathrm{ccm} \mathrm{Hg-lösung.}
\end{aligned}
$$


Also: $10 \mathrm{~cm}$ Harnmischung $=9,93 \mathrm{ccm} \mathrm{Hg}-$ lösung.

$0,99 \mathrm{~cm}$ Hg-lösung: $0,1 \% \stackrel{+}{\mathrm{U}}=(9,93 \mathrm{ccm}-5,5 \mathrm{ccm}): 0,45$.

Die Harnmischung enthält also $0,95 \%$ Harnstoff.

Weil aber $24,6 \mathrm{~cm}$ Harnmischung $=10 \mathrm{ccm}$ Harn, so enthält dieser $2,337 \%$ Harnstoff oder $1,092 \%$ Stickstoff.

$5 \mathrm{ccm}$ Harn $=0,0546 \mathrm{gr}$ Stickstoff.

Die Analysen nach Kjeldahl mit je 5 com Harn:

Analyse I. Gesammtvorlagen $=44 \mathrm{ccm} 1 / 10$ Schwefelsäure.

Gebraucht $=4,13 \mathrm{~cm} 1 / 10$ Natriumhyposulfitlösung.

Gebunden: $39,87 \mathrm{ccm} \mathrm{1/10}$ Schwefelsäure $=0,05598 \mathrm{gr}$ Stickstoff.

Analyse II. Gesammtvorlagen $=44 \mathrm{ccm} \mathrm{1/10} \mathrm{Schwefelsäure.}$

Gebraucht $4,12 \mathrm{ccm} \mathrm{1/10} \mathrm{Natriumhyposulfitlösung.}$

Gebunden $39,88 \mathrm{~cm}^{1} / 10$ Schwefelsäure $=0,05599 \mathrm{gr}$ Stickstoff.

Analyse I. $=0,05598 \mathrm{gr}$ Stickstoff.

$"$ II. $=0,05599, " n$

Mittel $=0,055985 \mathrm{gr}$ Stickstoff $=5 \mathrm{ccm}$ Harn.

$\check{\jmath} \mathrm{ccm}$ Harn nach KjeldahI $=0,055985$ gr Stickstoff.

๖ $" ~ "$ (Hg-lösung) $=0,054600, "$,

Differenz $=0,001385 \mathrm{gr}$ Stickstoff.

Fehler der Methode $=-2,4 \%$ des Stickstoffs.

Versuch 25 (Harn 99).

$200 \mathrm{ccm}$ Harn + $100 \mathrm{ccm}$ Liebig' sche Barytmischung.

$20 \mathrm{ccm}$ Harn gebrauchen zur Ausfällung des Chlors nach $\mathrm{Habel-}$ Fernholz 17,2 ccm Ag-lösung;

Also: $10 \mathrm{~cm}$ Harn $=8,6 \mathrm{ccm}$ Ag-lösung.

$150 \mathrm{ccm}$ Filtrat der Harnbarytmischung durch $3 \mathrm{ecm}$ verdünnter Salpetersäure neutralisirt und mit $86 \mathrm{ccm}$ Ag-lösung ausgefällt. Filtrat hiervon zur Titration benutzt.

Gemäss der Zusammensetzung der Harnmischung hat man:

$10 \mathrm{ccm}$ Harn + 5 cem Liebig' sche Barytmischung + 8,6 ccm Ag-lösung $+0,3 \mathrm{ccm}$ Salpetersäure $=23,9 \mathrm{ccm}$ Harnmischung.

Analyse I: $24,9 \mathrm{ccm}$ Harnmischung $=20,1 \mathrm{ccm}$ Hg-lösung.

$$
\begin{aligned}
& \text { "II: } 24,9, \quad \text { " } \quad=20,2, \quad \text { " } \\
& \text { "III: } 24,9, \quad, \quad=20,3, \quad \text {, } \\
& \text { Mittel }=20,2 \mathrm{~cm} \text { Hg-lösung. }
\end{aligned}
$$

Also: $10 \mathrm{ccm}$ Harmischung $=8,1 \mathrm{ccm} \mathrm{Hg}$-lösung.

$0,99 \mathrm{ccm} \mathrm{Hg}$-lösung: $0,1 \%$ \% $\mathrm{U}^{+}=(8,1-5,5): 0,262$.

$0,5 \%+0,262 \%=0,762 \% \stackrel{+}{\mathrm{U}}$ in der Mischung.

Weil aber $23,9 \mathrm{ccm}$ Harnmischung $\stackrel{i}{=} 10 \mathrm{~cm}$ Harn, so enthält dieser $1,821 \%$ Harnstoff oder $0,85123 \%$ Stickstoff, 
Die Analyse nach Kjeldahl mit je $5 \mathrm{ccm}$ Harn.

Analyse 1. Gesammtvorlagen $=37,0 \mathrm{~cm} 1 / 10$ Schwefelsäure.

Gebraucht $6,1 \mathrm{cem} 1 / 10$ Natriumhyposulfitlösung.

Gebunden 30,9 cem $1 / 10$ Schwefelsz̈ure $=0,04338 \mathrm{gr}$ Stickstoff.

Analyse II. Gesammtvorlagen $=37,0 \mathrm{ccm} 1 / 10$ Schwefelsäure.

Gebraucht $5,82 \mathrm{~cm} 1 / 10$ Natriumhyposulfitlösung.

Gebunden $31,18 \mathrm{ccm}^{1} / 10$ Schwefelsäure $=0,04378 \mathrm{gr}$. Stickstoff.

Analyse I: $=5 \mathrm{ccm}$ Harn $=0,04338 \mathrm{gr}$ Stickstoff.

$$
\begin{aligned}
" \mathrm{II}:=5, \quad "=0,04378, " \\
\text { Mittel }=0,04350 \mathrm{gr} \text { Stickstoff. }
\end{aligned}
$$

Also: $5 \mathrm{ccm}$ Harn nach $K \mathrm{Keldahl}=0,04358 \mathrm{gr}$ Stickstoff.

$$
\begin{aligned}
5 " \text { (Hg-lösung) } & =0,04256 ", " \\
\text { Differenz } & =0,00102 \mathrm{gr} \text { Stickstoff. }
\end{aligned}
$$

Fehler der Methode $=-2,3 \%$ des Stickstoffs.

Versuch 26 (Harn II).

$200 \mathrm{ccm}$ Harn + $100 \mathrm{ccm}$ Liebig'sche Barytmischung.

$20 \mathrm{ccm}$, Harn brauchen zur Ausfällung des Chlors nach HabelFernholz 27,15 ccm Ag-lösung.

Also $10 \mathrm{ccm}$ Harn $=13,575 \mathrm{~cm} \mathrm{Ag-lösung.}$

$150 \mathrm{ccm}$ Filtrat der Harnbarytmischung werden mit $3 \mathrm{ccm}$, verdünnter Salpetersäure neutralisirt, mit $135,75 \mathrm{ccm}$ Silberlösung ausgefällt und das Filtrat hiervon zur Titration benutzt.

Gemäss der Zusammensetzung der Harnmischung hat man:

$10 \mathrm{ccm}$ Harn $+5 \mathrm{~cm}$ Liebig'sche Barytmischung $+13,575 \mathrm{ccm}$ Ag-lösung $+0,3 \mathrm{ccm}$ Salpetersäure $=28,875 \mathrm{ccm}$ Harnmischung.

A nalys e I. $28,875 \mathrm{~cm}$ Harnmischung $=16,4 \mathrm{ccm}$ Hg-lösung.

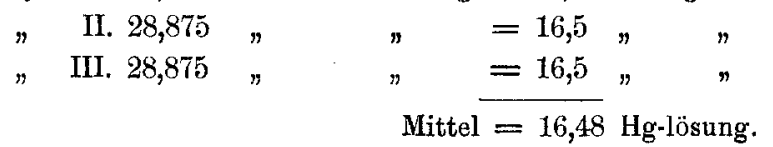

Also $10 \mathrm{~cm}$ Mischung $=5,7 \mathrm{ccm}$ Hg-lösung.

$0,99 \mathrm{ccm} \mathrm{Hg}-$ lösung : $0,1 \% \stackrel{+}{\mathrm{U}}=(5,7-5,5): 0,02$.

Die Harnmischung ist also eine $0,52 \%$ ige Lösung von Harnstoff.

Weil aber $28,875 \mathrm{ccm}$ Harnmischung $=10 \mathrm{ccm}$ Harn, so enthält dieser $1,501 \%$ Harnstoff oder $0,701 \%$ Stickstoff.

$5 \mathrm{ccm}$ Harn $=0,03505 \mathrm{gr}$ Stickstoff.

Die Analysen nach Kjeldahl mit je 5 ccm Harn:

Analyse I. Gesammtvorlagen $=29 \mathrm{~cm} 1 / 10$ Schwefelsäure.

Gebraucht $=2,95 \mathrm{ccm} 1 / 10$ Natriumhyposulfitlösung.

Gebunden $26,05 \mathrm{ccm} 1 / 10$ Schwefelsäure $=0,03657 \mathrm{gr}$ Stickstoff.

E. Pfüger, Archiv f. Physiologie. Bd. XI. 
A nalyse II. Gesammtvorlagen $=29 \mathrm{ccm} \mathrm{1/10} \mathrm{Schwefelsäure.}$

Gebraucht $=3,07 \mathrm{~cm} \mathrm{1/10} \mathrm{Natriumhyposulfitlösung.}$

Gebunden 25,93 ccm $1 / 10$ Schwefelsäure $=0,03641 \mathrm{gr}$ Stickstoff.

Analyse I. $=5 \mathrm{ccm}$ Harn $=0,03657 \mathrm{gr}$ Stickstoff.

$$
\begin{aligned}
\text { II. }=5, \quad "=0,03641 \mathrm{gr} & = \\
\text { Mittel } & =0,03649 \mathrm{gr} \text { Stickstoff. }
\end{aligned}
$$

$5 \mathrm{ccm}$ Harn nach Kjeldahl $=0,03649 \mathrm{gr}$ Stickstoff.

5 " "(Hg-lösung) . =0,03506 gr "

Differenz $=0,00143 \mathrm{gr}$ Stickstoff.

Also Fehler der Methode $=-3,9 \%$ des Stickstoffs.

\section{Versuch 27 (Harn IV).}

$200 \mathrm{ccm}$ Harn $+100 \mathrm{ccm}$ Liebig'sche Barytmischung.

$20 \mathrm{ccm}$ Harn gebrauchen zur Ausfällung des Chlors nach HabelFernholz 20,85 ccm Ag-lösung.

Also $10 \mathrm{ccm}$ Harn $=10,175 \mathrm{~cm}$ Ag-lösung.

$150 \mathrm{ccm}$ Filtrat der Harnbarytmischung durch $3 \mathrm{ccm}$ verdünnter Salpetersäure neutralisirt und mit $101,75 \mathrm{ccm} \mathrm{Ag-lösung} \mathrm{ausgefällt.} \mathrm{Das} \mathrm{Filtrat}$ hiervon zur Titration benutzt.

Gemäss der Zusammensetzung der Mischung hat m.zn:

$10 \mathrm{~cm}$ Harn + 5cam Liebig'sche Barytmischung $+10.175 \mathrm{ccm}$ Ag-lösung $+0,3 \mathrm{ccm}$ Salpetersäure $=25,475 \mathrm{ccm}$ Harnmischung.

A n aly se I. $25,475 \mathrm{ccm}$ Harnmischung $=14,8 \mathrm{ccm}$ Hg-lösung.

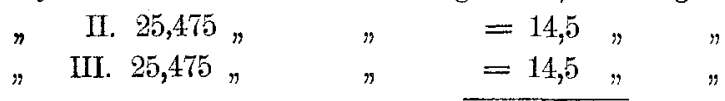

Mittel $=14,6 \mathrm{ccm}$ Hg-lissung.

Also $10 \mathrm{ccm}$ Harn-Mischung $=5,7 \mathrm{ccm}$ Hg-lösung.

$0,99 \mathrm{ccm} \mathrm{Hg-lösung} \mathrm{:} 0,1 \% \stackrel{+}{\mathrm{U}}=(5,7-5,5): 0,02$.

Also enthält die Mischung $0,52 \%$ Harnstoff.

Weil aber $25,475 \mathrm{ccm}$ Mischung $=10 \mathrm{~cm}$ Harn, so enthält dieser $1,325 \%$ Harnstoff oder $0,6193 \%$ Stickstoff.

$$
5 \mathrm{cem} \text { Harn }=0,030965 \text {. }
$$

Die Analyse nach $\mathrm{Kjeldahl}$ mit je $5 \mathrm{ccm}$ Harn:

A nalyse I. Gesammtvorlagen $=28 \mathrm{~cm} \mathrm{1/10} \mathrm{Schwefelsäure.}$

Gebraucht $5,37 \mathrm{~cm} \mathrm{1/10} \mathrm{Natriumhyposulfitlösung.}$

Gebunden $\quad 22,63^{1} / 10$ Schwefelsäure $=0,03177 \mathrm{gr}$ Stickstoff.

Analyse II. Gesammtvorlagen $=28 \mathrm{ccm} 1 / 10$ Schwefelsäure.

Gebraucht $5,35 \mathrm{ccm} 1 / 10$ Natriumhyposulfitlösung.

Gebunden $=22,65 \mathrm{ccm} 1 / 10$ Schwefelsäure $=0,03180 \mathrm{gr}$ Stickstoff.

A nalyse I. 5 ccm Harn $=0,03177 \mathrm{gr}$ Stickstoff.

"II. $5 n \quad "=0,03180 "$,

Mittel $=0,031785 \mathrm{gr}$ Stickstoff. 
Also:

う̌cm Harn nach Kjeldahl $=0,031785 \mathrm{gr}$ Stickstoff.

$5 "$ " (Hg-lösung) $=0,030965, " n$

Differenz $=0,000820 \mathrm{gr}$ Stickstoff.

Fehler der Methode $=-2,5 \%$ des Stickstoffs.

\section{Versuch 28 (Harn V).}

$200 \mathrm{~cm}$ Harn $+100 \mathrm{~cm}$ Liebig'sche Barytmischung.

$20 \mathrm{~cm}$ Harn brauchen zur Ausfällung des Chlors nach Habel-Fernholz 18,2 ccm Ag-lösung.

Also $10 \mathrm{ccm}$ Harn $=9,1 \mathrm{ccm}$ Ag-lösung.

$150 \mathrm{ccm}$ Filtrat der Harnbarytmischung durch $3 \mathrm{ccm}$ verdünnter Salpetersäure neutralisirt und mit $91 \mathrm{ccm} \mathrm{Ag-lösung} \mathrm{ausgefällt.} \mathrm{Das} \mathrm{Filtrat}$ hiervon zur Titration benutzt.

Gèmäss der Zusammensetzung der Harnmischung hat man:

$10 \mathrm{ccm}$ Harn $+5 \mathrm{ccm}$ Liebig'sche Barytmischung $+9,1 \mathrm{ccm} \mathrm{Ag-}$ lösung $+0,3 \mathrm{ccm}$ Salpetsrsäure $=24,4 \mathrm{ccm}$ Harnmischung.

An alys e I. $24,4 \mathrm{ccm}$ Harnmischung $=9,8 \mathrm{~cm}$ Hg-lösung.

\begin{tabular}{|c|c|c|c|}
\hline II. 24,4 & $n$ & $n$ & $=9,6$ \\
\hline III. 24,4 & $\eta$ & $n$ & $=9,7$ \\
\hline
\end{tabular}

Mittel $=9,7 \mathrm{ccm} \mathrm{Hg}$-lösung.

Also $10 \mathrm{~cm}$ Harnmischung $=3,98 \mathrm{~cm}$ Hg-lösung.

$0,99 \mathrm{ccm}$ Hg-lösung: $: 0,1 \% \stackrel{+}{\mathrm{U}}=(5,5-3,98): 0,153$.

$0,5 \%-0,153 \%=0,347 \%$ Harnstoff in der Harnmischung.

Weil aber $24,4 \mathrm{ccm}$ Harnmischung $=10 \mathrm{ccm}$ Harn, so enthält dieser $0,84668 \%$ Harnstoff oder $0,3958 \%$ Stickstoff.

$5 \mathrm{ccm}$ Harn also $=0,01979 \mathrm{gr}$ Stickstoff.

Die Analyse nach $\mathrm{Kjeldahl} \mathrm{mit} \mathrm{je} 5 \mathrm{ccm}$ Harn.

Analyse I. Gesammtvorlagen $=21 \mathrm{ccm} 1 / 10$ Schwefelsäure.

Gebrancht $6,90 \mathrm{ccm} \mathrm{1/10} \mathrm{Natriumhyposulfitlösung.}$

Gebunden 14,1 ccm 1/10 Schwefelsäure $=0,019796 \mathrm{gr}$ Stickstoff.

A nalyse II. Gesammtvorlagen $=21,0 \mathrm{~cm} 1 / 10$ Schwefelsäure.

Gebraucht $6,92 \mathrm{~cm} 1 / 10$ Natriumhyposulfitlösung. Also

gebunden 14,08 ccm 1/10 Schwefelsäure $=0,019768 \mathrm{gr}$ Stickstoff.

Analyse I. $5 \mathrm{ccm}$ Harn $=0,019796 \mathrm{gr}$ Stickstoff.

II. $5, \quad=0,019768_{n}$,

Mittel $=\overline{0,019782 \mathrm{gr}}$ Stickstoff.

$5 \mathrm{ccm}$ Harn nach $\mathrm{Kjel} \mathrm{dahl}=0,019782 \mathrm{gr}$ Stickstoff.

$5 "$ (Hg-lösung) $=0,019790$,

Differenz $=0,000008 \mathrm{gr}$ Stickstoff.

Fehler der Methode $=+0,04 \%$ des Stickstoffs. 
Generaltabelle.

Titration des Harns mit Rautenberg'scher Quecksilberlösung.

\begin{tabular}{|c|c|c|c|c|c|c|c|}
\hline \multirow{2}{*}{$\begin{array}{c}\text { Nummer } \\
\text { des } \\
\text { Versuchs. }\end{array}$} & \multicolumn{4}{|c|}{$\begin{array}{l}5 \mathrm{ccm} \text { Harn enthalten } \\
\text { Stickstoff nach }\end{array}$} & \multicolumn{2}{|c|}{$\begin{array}{l}\text { Fehler von Rautenberg's } \\
\text { Methode. }\end{array}$} & \multirow{2}{*}{$\begin{array}{c}\text { Nummer } \\
\text { des } \\
\text { Harns. }\end{array}$} \\
\hline & \multicolumn{2}{|l|}{ Kjeldahl. } & \multicolumn{2}{|c|}{ Rautenberg. } & + Fehler. & - Fehler. & \\
\hline 1 & 0,0390 & $\mathrm{gr}$ & 0,03671 & $\mathrm{gr}$ & & $-5,7 \%$ & 1 \\
\hline 2 & 0,03700 & $"$ & 0,03595 & $"$ & & $-2,8$, & 15 \\
\hline 3 & 0,03204 & $"$ & 0,03230 & $n$ & $+0,8 \%$ & & 4 \\
\hline 4 & 0,05150 & , & 0,05176 & , & $+0,5 \quad$ & & 4 \\
\hline 5 & 0,03594 & $"$ & 0,03797 &, & $+5,6$ & & 22 \\
\hline 6 & 0,02620 & , & 0,02745 & " & $+4,8$, & & 21 \\
\hline 7 & 0,034313 & , & 0,036794 & , & $+7,2$ & & 23 \\
\hline 8 & 0,03138 & " & 0,03125 & $n$ & & $-0,4$, & 18 \\
\hline 9 & 0,03819 & , & 0,04081 & $"$ & $+6,8$ & & 50 \\
\hline 10 & 0,05102 & , & 0,05361 & $"$ & $+5,1 \quad$ & & 3 \\
\hline 11 & 0,04317 & $n$ & 0,04429 &, & $+2,6$ & & 1 \\
\hline 12 & 0,06148 & $"$ & 0,06210 & $n$ & $+1,0$ & & 3 \\
\hline 13 & 0,03249 & $\eta$ & 0,03233 &, & & $-0,5$, & 18 \\
\hline 14 & 0,04458 & $"$ & 0,044558 & $n$ & $+2,2$ & & 25 \\
\hline 15 & 0,05681 & $"$ & 0,05810 & $"$ & $+2,3$ & & 1 \\
\hline 16 & 0,035128 & , & 0,036786 & , & $+4,7$ & & 24 \\
\hline 17 & 0,04565 & , & 0,04485 & $n$ & & $-1,8$, & 1 \\
\hline 18 & 0,05049 & " & 0,04987 & $"$ & & $-1,2$, & 2 \\
\hline 19 & 0,02889 & $"$ & 0,02945 & $"$ & $+1,6$ & & 18 \\
\hline 20 & 0,06230 & $"$ & 0,06255 & $"$ & $+0,4$ & & 99 \\
\hline 21 & 0,04163 & $"$ & 0,04075 & $"$ & & $-2,1$, & 3 \\
\hline 22 & 0,02630 & $"$ & 0,02610 &, & & $-0,8$, & 5 \\
\hline 23 & 0,02629 & $"$ & 0,026165 & , & & $-0,5$, & 1 \\
\hline 24 & 0,055985 & $"$ & 0,05460 & $"$ & & $-2,4$, & 3 \\
\hline 25 & 0,04358 & $n$ & 0,04256 & ", & & $-2,3$, & 99 \\
\hline 26 & 0,03649 & $n$ & 0,03506 & $n$ & & $-3,9$ " & 2 \\
\hline 27 & 0,031785 &, & 0,030965 & , & & & 4 \\
\hline 28 & 0,019782 & $"$ & 0,01979 &, & $+0,04$ & & 5 \\
\hline & & & Summ & & $+45,64 \%$ & $-26,9 \%$ & \\
\hline
\end{tabular}


Aus der Generaltabelle folgt der mittlere Fehler $+0,7 \%$ des Stickstoffs.

Betrachtet man aber die Versuche, die so in der Zeit nach einander angestellt sind, wie sie in der Tabelle auf einander folgen, so bemerkt man, dass in der ersten Hälfte der Versuche der Stickstoff meist zu gross, oft viel zu gross gefunden wurde, während in der zweiten Hälfte der Versuche die Sache sich in sofern umgekehrt verhält, als der Beobachtungsfehler gewöhnlich negativ erscheint.

Bei Betrachtung der Tabelle fällt ferner auf, dass die erste Hälfte der Versuche absolut grössere Beobachtungsfehler von negativem, besonders aber positivem Vorzeichen aufweist als die zweite Hälfte.

Der Grund dieser Verschiedenheit der Resultate in den ersten und letzten Versuchen liegt einmal darin, dass mit fortschreitender Uebung die Analysen genauer ausfielen; vielleicht spielt auch eine Rolle die Chlorbestimmung nach Mohr, weshalb diese sehr bald durch die exacte von $\mathrm{Habel-Fernholz} \mathrm{ersetzt} \mathrm{wurde,} \mathrm{um} \mathrm{diese}$ Complication zunächst zu eliminiren. Vorzitglich aber kommt in Betracht, dass immer mehr dahin gestrebt wurde, gegen das Ende der Titration das Vorhandensein eines grösseren Ueberschusses von kohlensaurem Kalk zu vermeiden. Man muss deshalb oft mit kleinen Quantitäten von kohlensaurem Kalk neutralisiren, viel schuitteln und fortwährend mit gutem neutralen Lackmuspapier prïfen, ob auch genug zugesetzt, d. h. alkalische Reaction bemerkbar wird. Verfährt man in dieser Weise, dann wird etwas zu wenig Stickstoff gefunden, wie ein Blick auf die Tabelle zeigt. -

Fine spätere Untersuchung soll die Frage behandeln, ob ein Ueberschuss an Silber bei der Ausfällung des Chlors ohne Bedeutung für das Resultat ist, wie es Pfeiffer behauptet, da das allerdings ein in Betracht kommender Vortheil der Methode wäre.

An ein paar Versuchen kann das bei der wechselnden $\mathrm{Za}$ sammensetzung des Harns natiurlich nicht entschieden werden, sodass eine grössere Zahl von Analysen nothwendig wird.

Um die Resultate dieser Untersuchung zusammenzufassen bemerke ich zum Schlusse folgendes:

Durch meine und Bohland's Untersuchungen ist festgestellt, dass von 100 Gewichtstheilen des im Menschenharn enthaltenen Stickstoffs 13 Gewichtstheile im Mittel aicht in Harn- 
stoff, sondern in anderen Körpern enthalten sind. Da nun die Methode von Rantenberg annähernd das Gewicht des gesammten Stickstoffs des Menschenharns ergibt, so kann sie nicht als quantitative Analyse des Harnstoffs angesehen werden.

Rautenberg's Methode ist also in der That eine Analyse des Stickstoffs. Streng genommen heisst der Titer nicht:

$1 \mathrm{ccm} \mathrm{R}$-Hg-lösung $=0,01 \mathrm{gr}$ Harnstoff, sondern:

$1 \mathrm{ccm} \mathrm{R}^{\prime}$-Hg-lösung $=0,004674 \mathrm{gr}$ Stickstoff.

Wer endlich selbst meine Methode mit der von Rautenberg vergleicht, wird finden, dass der Index bei der letzteren mit weniger Schärfe hervortritt.

(Aus dem physiologischen Laboratorium der Universität Jena.)

\section{Die Wahrnehmung der Schallrichtung mittelst der Bogengänge.}

Zum Theil nach Versuchen des Herrn Cand. d. Med. K. Schaefer.

Von

W. Preyer.

Einleitung.

Während es keinem Zweifel unterliegt, dass jede sinnliche Empfindung im Augenblick ihres Auftretens im Bewusstseinsfelde irgendwelchen räumlichen Charakter hat, ist es für sämmtliche Sinnesgebiete und die Organempfindungen fraglich, was die jedem einzelnen Sinneseindruck ausserhalb und innerhalb des Körpers und an seiner Oberfläche zukommende Localisation bestimmt. 